\title{
A Novel Integrated Stability Control Based on Differential Braking and Active Steering for Four-axle Trucks
}

\author{
Buyang Zhang ${ }^{1}$, Changfu Zong ${ }^{2}$, Guoying Chen ${ }^{2 *}$, Yanjun Huang ${ }^{3}$ and Ting $\mathrm{Xu}^{1}$
}

\begin{abstract}
Differential braking and active steering have already been integrated to overcome their shortcomings. However, existing research mainly focuses on two-axle vehicles and controllers are mostly designed to use one control method to improve the other. Moreover, many experiments are needed to improve the robustness; therefore, these control methods are underutilized. This paper proposes an integrated control system specially designed for multi-axle vehicles, in which the desired lateral force and yaw moment of vehicles are determined by the sliding mode control algorithm. The output of the sliding mode control is distributed to the suitable wheels based on the abilities and potentials of the two control methods. Moreover, in this method, fewer experiments are needed, and the robustness and simultaneity are both guaranteed. To simplify the optimization system and to improve the computation speed, seven simple optimization subsystems are designed for the determination of control outputs on each wheel. The simulation results show that the proposed controller obviously enhances the stability of multi-axle trucks. The system improves $68 \%$ of the safe velocity, and its performance is much better than both differential braking and active steering. This research proposes an integrated control system that can simultaneously invoke differential braking and active steering of multi-axle vehicles to fully utilize the abilities and potentials of the two control methods.
\end{abstract}

Keywords: Differential braking, Active steering, Vertical tire force calculation, Multi-axle truck, Integrated control

\section{Introduction}

Rollover and lateral instability are two common issues of heavy-duty trucks, which can result in fatal accidents and massive losses. Differential braking (DB) and active steering (AS) are two of the most effective methods to improve the vehicle yaw stability and untripped rollover accidents [1]. DB and AS systems have their own disadvantages, and researchers have proposed several integrated controllers to overcome them. However, existing research mainly focuses on two-axle vehicles or multi-axle vehicles with two-axle equivalent models [2]. Heavy-duty trucks usually have more than two axles for increased transportation efficiency [3]. DB or AS individually might not control the lateral instability and rollover accident of

\footnotetext{
*Correspondence: cgy-011@163.com

${ }^{2}$ State Key Laboratory of Automotive Simulation and Control, Jilin University, Changchun 130022, China

Full list of author information is available at the end of the article
}

multi-axle trucks, because multi-axle trucks usually have higher center of gravity and heavier mass and they work under difficult conditions. In a multi-axle truck, distributing the reasonable braking torques and steering angles to suitable wheels is complex. The integrated controller design in a two-axle vehicle cannot be used directly in a multi-axle vehicle. The integrated control system for a multi-axle truck has not been fully studied. Therefore, a practical and effective integrated control system is needed urgently, especially for multi-axle trucks.

DB systems can slow down the vehicle and make the driver feel safe under high-speed conditions. In addition, the trajectory deviation caused by DB is smaller than that caused by AS. DB systems can also be easily implemented in conventional braking systems. For instance, electronic stability programs, electronic stability control (ESC), and direct yaw moment control (DYC) are widely used in heavy-duty vehicles, which apply DB or driving torques on wheels such that the vehicle active safety can 
be greatly improved [4-6]. By contrast, AS systems can generate an external yaw movement by actively turning the vehicle wheels in a small range [7]. Three types of AS, namely active front steering (AFS) [8, 9], active rear steering (ARS) [10], and four-wheel steering [11], are defined in existing literature. The AS system cannot generate the required yaw moment under certain circumstances [12]. The control effects and limits of AS and DB have been extensively discussed in literature. Koibuchi et al. [13] discussed the pros and cons of the DB system for a passenger car and concluded that when an inward moment is needed, the braking force is applied to the rear-inner wheel and vice versa. Yang et al. [14] showed the effects of all-wheel AS for a three-axle truck. Balázs et al. [15] discussed the steering angle limit and steering rate limit and proposed different actuation-level steering control methods for articulated vehicles. They presented the effects and limitations of each control method without comparing them and without providing selection criteria for specific conditions.

Most integrated control methods work in two steps. First, the total control inputs are calculated. Then, they are distributed using a coordination logic, rule, or optimization process. The controller in Ref. [16] is developed on the basis of a two-level control structure. In the upper level, the required yaw moment and rear steering angle are calculated, while in the lower level, the braking torque is distributed. The most important part of the integrated control is the coordination of DB and AS. A popular method is the phase plane $(\beta, \dot{\beta})$ analysis. In Ref. [17], AFS and DB are activated together or separately based on regions of stability index derived from the phase plane analysis. In Ref. [18], AFS and DYC have been integrated via fuzzy logic based on stability index obtained by the phase plane analysis. The phase plane analysis is widely discussed and applied for vehicle stability analysis and control [19-21]. Empirical methods such as setting gains $[22,23]$ and fuzzy logic $[18,24]$ are also employed in integrated control methods. They are practical, but they require significant simulation or experimental data. Other researchers use optimization methods and model predictive control (MPC) to distribute AS and DB [2527]. They cannot completely replace the functions of rules or logic. The coordination still mainly depends on the rule and logic design. The MPC or optimization may also make the control system complex. In other research, $\mathrm{DB}$ and $\mathrm{AS}$ are used to compensate for the other when one of them has reached its saturation limit. In Ref. [28], ARS was used to extend tire limitations, and four-wheel drive/ESC was used to optimally distribute the longitudinal forces. In Ref. [29], researchers controlled the vehicle lateral stability by DB and AS sequentially. Once the vehicle stability cannot be maintained only by using $\mathrm{DB}$, AS starts to work. In Ref. [30], the braking system is used to generate large lateral forces when the steering tire is saturated. In Ref. [31], the priority of DB is set lower than that of AFS, and DB is functional only when activated. Existing studies have not compared DB and AS, and the characteristics of multi-axle truck are also not considered. Moreover, most studies have not activated different control methods at the same time [28-33]. The advantages of DB and AS can only be found when they are activated. If they are activated simultaneously, the integrated control system can genuinely overcome the disadvantages of $\mathrm{DB}$ and $\mathrm{AS}$. If the integrated controller has an optimization system in the control process, DB and AS can be activated simultaneously. However, for a multiaxle truck, more axles mean more variables, making the optimization more complex and slower.

This paper proposes a novel integrated control system designed for a four-axle truck with fewer experiments. AS and DB can work simultaneously to improve the roll and yaw stability. To improve the robustness of the control system without many experiments, a novel comparison method for $\mathrm{DB}$ and AS is also proposed. This research is organized as follows. In Section 2, a novel method to accurately predict vertical tire forces in a fouraxle truck is proposed. In Section 3, the effects of DB and AS are analyzed and compared and the limits of AS and DB are presented. In Section 4, a sliding mode controller is designed to determine the total yaw moment and lateral force. They are distributed on the basis of the DB and AS analysis results and transferred by optimization systems to steering angles and braking forces to each wheel. Because DB and AS are integrated on the basis of a real-time analysis of their ability and potential, the system has better robustness. In Section 5 , the simulation results show that the proposed control system can obviously enhance the stability of multi-axle trucks. Finally, the conclusions are drawn and future work is discussed. Based on the results, this paper has proposed an integrated control system that can reasonably solve the problems discussed above and utilize the ability of two stability control systems further. Moreover, this paper proposes a comparison method of DB and AS, which can help for better coordination between them.

\section{Tire Vertical Forces of a Four-axle Truck}

When analyzing DB and AS, the vertical forces of tires for the four-axle truck need to be accurately estimated beforehand. In existing methods, a dynamic load transfer coefficient is used, making the calculation more complex. Therefore, a novel method is proposed to identify these vertical forces and avoid using this coefficient. Assume 
that the variations of tire vertical forces are only caused by the lateral acceleration, longitudinal acceleration, roll angle, and roll angle rate. The four-axle truck body is separated into three parts and the center of gravity (CG) of the truck is not necessary. As shown in Figure 1, $c g_{1}$, $c g_{2}$, and $c g_{3}$ are the local CG points of each part. Part 1 consists of the unloaded truck and first axle; the height of $c g_{1}$ is equal to that of the unloaded truck. Part 2 consists of half the load and second axle; $c g_{2}$ refers to the CG of the front part of the cargo, which is identical to the height of the CG of the entire cargo. Part 3 consists of the other half part of load, third axle, and fourth axle; $c g_{3}$ is the CG of the rear part of the cargo. Several hypothetical internal forces $\left(F_{z a l i, z a r i}, i=1,2,3\right)$ are introduced to each part. The symbols used in figures and equations are introduced in the Nomenclature (in Appendix). The tire vertical forces can be defined as Eq. (1):

$$
F_{z r i, z l i}=F_{z r i_{0}, z l l_{0}}+\Delta F_{z r i, z l i}, \quad i=1,2,3,4,
$$

where $F_{z r i_{0}, z l i_{0}}$ represents the static vertical forces of tires and can be easily obtained from sensors or calculation. $\Delta F_{z r i, z l i}$ is the vertical tire force variation. Equations (2)-(10) are derived from the conservation of moment. As an example of the modeling of different parts, Figure 2 shows a simple model of Part 1, and Eqs. (2)-(4) can be derived easily.

Part 1

$$
\begin{aligned}
\Delta F_{z r 1, z l 1}=\Delta & F_{z m r 1, z m l 1}-F_{z a r 1, z a l 1} \pm \frac{K_{b 1} \varphi}{H} \\
\Delta F_{z m r 1, z m l 1}= & \pm \frac{m_{\nu} a_{y} h_{1}}{H} \cos (\varphi) \pm \cdots \\
& \pm \frac{\left(K_{1} \varphi+C_{1} \dot{\varphi}\right)}{H} \pm \frac{m_{\nu} g h_{r 1} \sin \varphi}{H},
\end{aligned}
$$

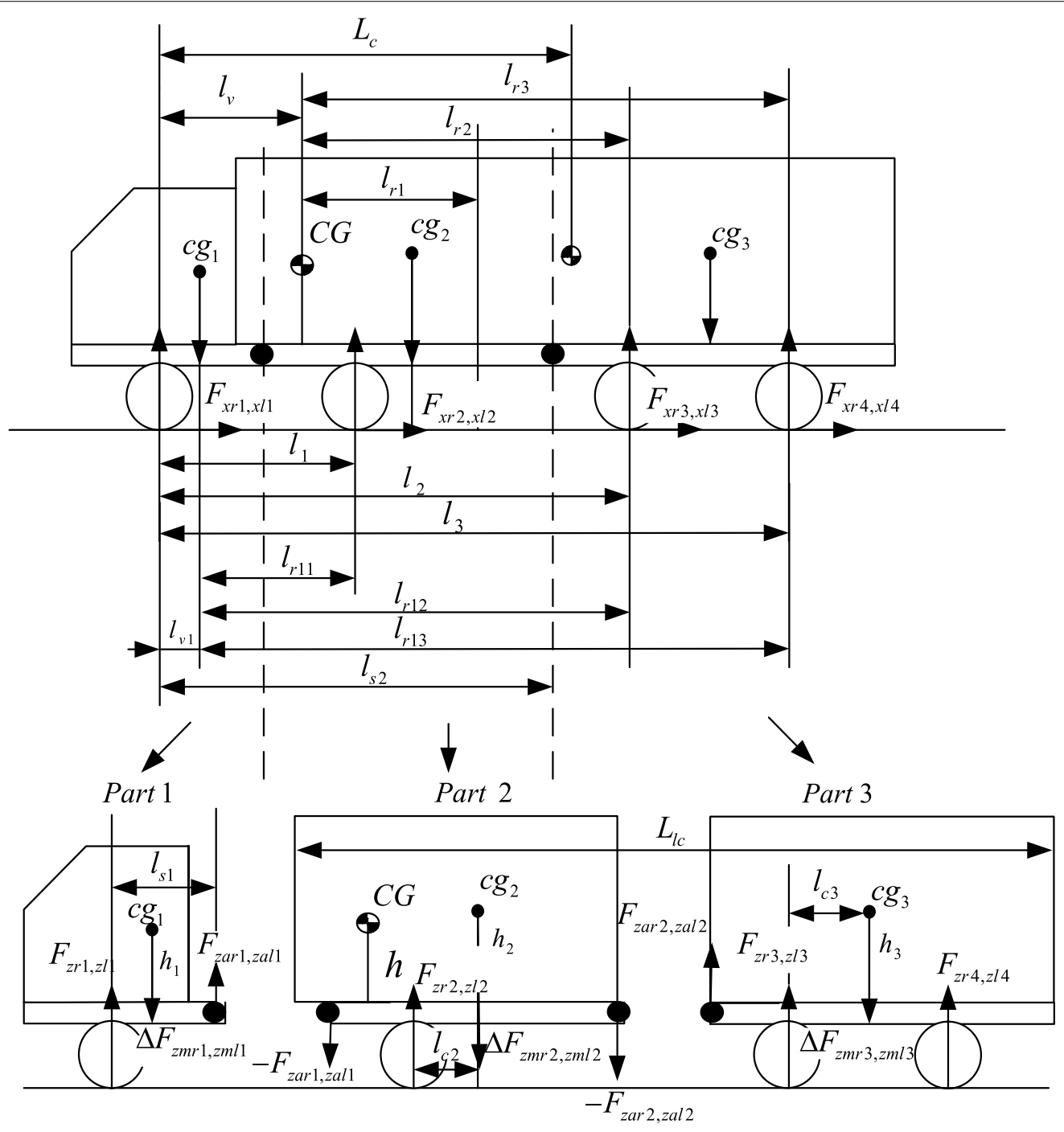

Figure 1 Four-axle truck with three separated parts 


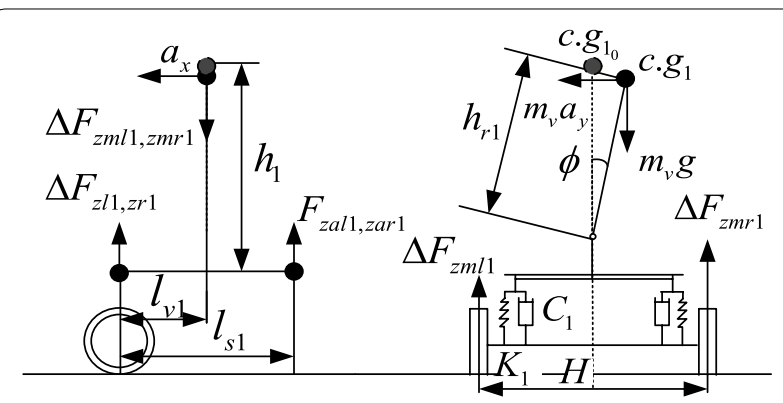

Figure 2 Model of Part 1

$$
F_{z a r 1, z a l 1}=\frac{\Delta F_{z m r 1, z m l 1} l_{v 1}+m_{v} a_{x} h_{1} / 2}{l_{s 1}} .
$$

Part 2

$$
\Delta F_{z r 2, z l 2}=-\left(F_{z a r 2, z a l 2}+F_{z a r 1, z a l 1}-\Delta F_{z m r 2, z m l 2}\right) \pm \frac{K_{b 2} \varphi}{H},
$$$$
\Delta F_{z m r 2, z m l 2}= \pm \frac{m_{2} a_{y} h_{2}}{H} \cos (\varphi) \pm \frac{\left(K_{2} \varphi+C_{2} \dot{\varphi}\right)}{H}
$$$$
\pm \frac{m_{2} g h_{r 2} \sin \varphi}{H}
$$$$
F_{z a r 2, z a l 2}=\frac{-\left(F_{z a r 1, z a l 1} l_{r 11} / 2+m_{2} a_{x} h_{2} / 2\right)}{\left(l_{r 12}-l_{r 11}-l_{c 2}\right) / 2+l_{c 2}}+\cdots
$$$$
+\frac{\Delta F_{z m r 2, z m l 2} l_{c 2}}{\left(l_{r 12}-l_{r 11}-l_{c 2}\right) / 2+l_{c 2}} \text {. }
$$

Part 3

$$
\begin{aligned}
\Delta F_{z m r 3, z m l 3}= & \pm \frac{m_{3} a_{y} h_{3}}{H} \cos (\varphi) \pm \frac{\left(K_{3} \varphi+C_{3} \dot{\varphi}\right)}{H} \\
& \pm \frac{m_{3} g h_{r 3} \sin \varphi}{H}, \\
\Delta F_{z r 3, z l 3}= & \frac{\left(-F_{z a r 2, z a l 2}\left(\frac{\left(l_{r 12}-l_{r 11}-l_{c 2}\right)}{2}+\left(l_{r 13}-l_{r 12}\right)\right)\right)}{l_{r 13}-l_{r 12}}+\cdots \\
+ & \frac{\frac{m_{3} a_{x} h_{3}}{2}+\Delta F_{z m r 3, z m l 3}\left(l_{r 13}-l_{r 12}-l_{c 3}\right)}{l_{r 13}-l_{r 12}} \pm \frac{K_{b 3} \varphi}{H},
\end{aligned}
$$

$$
\Delta F_{z r 4, z l 4}=\Delta F_{z r 3, z l 3}+F_{z a r 2, z a l 2}+\Delta F_{z m r 3, z m l 3} \pm \frac{K_{b 4} \varphi}{H},
$$

$$
\left\{\begin{array}{l}
l_{s 1}=l_{v 1}+l_{r 11} / 2 \\
l_{s 2}=\left(l_{r 12}-l_{r 11}-l_{c 2}\right) / 2+l_{c 2}+l_{1} \\
l_{c 2}=\left(L_{l c}-\frac{L_{c}}{2}\right)+\frac{L_{c}}{4}-\left(l_{v 1}+l_{r 11}\right) \\
l_{c 3}=\left(L_{l c}-\frac{L_{c}}{2}\right)+\frac{3}{4} L_{c}-\left(l_{v 1}+l_{r 12}\right) .
\end{array}\right.
$$

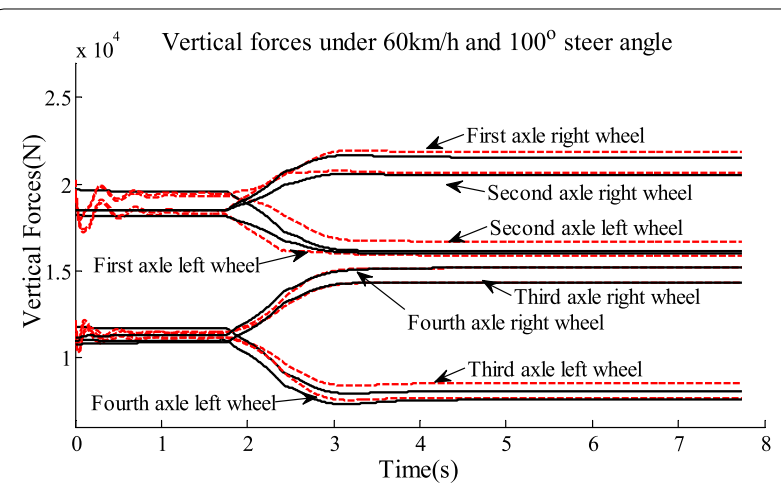

Figure 3 Comparison of tire vertical forces model and tire vertical forces from TruckSim

Figure 3 shows the comparison of results from calculation and TruckSim. The loaded truck is $5000 \mathrm{~kg}$, and the unloaded truck is $4457 \mathrm{~kg}$. The truck in TruckSim only has one steering axle. The maximum percentage deviation of vertical forces is $9.19 \%$.

\section{Analyses of Differential Braking and Active Steering}

Both AS and DB controllers are designed as yaw rate feedback controllers. Therefore, the yaw moment or yaw rate generated by AS or DB systems can act as an index to evaluate their control ranges and potentials. In this section, these two indexes of both $\mathrm{DB}$ and $\mathrm{AS}$ are analyzed and estimated. A novel comparison method of DB and AS is also proposed and used in the integrated control system.

\subsection{Active Steering}

Assuming that AS can just be applied on one axle, it can be activated hydraulically as electronic trailer steering system. The tire sideslip angle limit of the front steering axle can be reached easily. Therefore, the AS system of this fouraxle truck can act on any axle except the front axle. Several assumptions are made: (1) The AS angle is within $\pm 8^{\circ}$. (2) The AS system can respond so fast that the system states can be assumed to be invariant during each time interval.

As shown in Figure 4, $F_{X L i, X R i}$ and $F_{Y L i, Y R i}$ are longitudinal forces and lateral forces of tires along the lateral and longitudinal vehicle axes, respectively. Assuming the truck is turning left, the steering angle and inward yaw moment are positive. From Figure 4, according to the conservation of moment, the yaw moment and lateral force of the truck can be derived as follows:

$$
\begin{aligned}
M_{z}= & \left(F_{Y L 1}+F_{Y R 1}\right) l_{v}-\sum_{i=2}^{4}\left(\left(F_{Y L i}+F_{Y R i}\right)\left(l_{i-1}-l_{v}\right)\right)+\cdots \\
& +\frac{H}{2} \sum_{i=2}^{4}\left(F_{X R i}-F_{X L i}\right),
\end{aligned}
$$




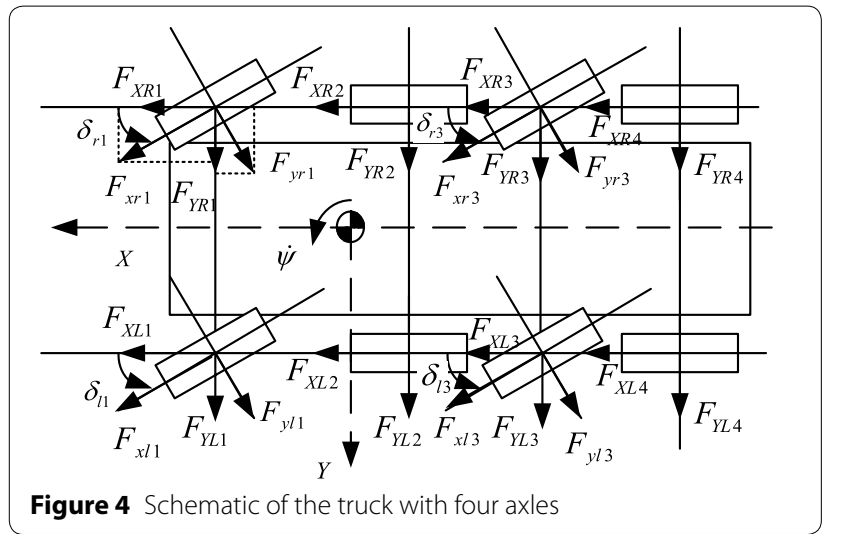

$$
F_{y_{\text {sum }}}=m a_{y}=\sum_{i=1}^{4} F_{Y R i}+\sum_{i=1}^{4} F_{Y L i} .
$$

Assuming no steering angle and a very small longitudinal force at the beginning, the lateral forces of tires $F_{Y R i, Y L i}$ can be represented by Eq. (14) using a simplified Magic formula [in Appendix, Eq. (50)].

$$
\begin{aligned}
F_{Y R i, Y L i}= & F_{z r i, z l i}\left(P_{v y 1}+\frac{P_{v y 2}\left(F_{z r i, z l i}-F_{z o}\right)}{F_{z o}}\right)+\cdots \\
+ & \left(2 P_{k y 1} F_{z o} \arctan \left(\frac{F_{z r i, z l i}}{F_{z o} P_{k y 2}}\right)\right. \\
& \left.\left(P_{h y 1}+\alpha_{r i, l i}+\frac{P_{h y 2}\left(F_{z r i, z l i}-F_{z o}\right)}{F_{z o}}\right)\right) \\
\frac{\mathrm{d} M_{z}}{\mathrm{~d} \alpha_{r i, l i}}= & -2 F_{z o} P_{k y 1} k_{t i} \arctan \left(\frac{F_{z r i, z l i}}{F_{z o} P_{k y 2}}\right)\left(l_{i-1}-l_{v}\right) \\
= & -2 F_{z o} P_{k y 1} k_{t i} \arctan \left(\frac{F_{z r i, z l i}}{F_{z o} P_{k y 2}}\right) l_{r i}, \\
\frac{\mathrm{d} a_{y}}{\mathrm{~d} \alpha_{r i, l i}}= & \frac{2 F_{z o} P_{k y 1} k_{t i} \arctan \left(\frac{F_{z i r z l i}}{F_{z o} k_{k y 2}}\right)}{m}, \\
\Delta M_{z s t i}= & \frac{\mathrm{d} M_{z}}{\mathrm{~d} \alpha_{r i}}\left(\Delta \alpha_{r i}\right)+\frac{\mathrm{d} M_{z}}{\mathrm{~d} \alpha_{l i}}\left(\Delta \alpha_{l i}\right) \\
= & 2 F_{z o} P_{k y 1} k_{t i}\left(\frac{F_{z r i}+F_{z l i}}{F_{z o} P_{k y 2}}\right) l_{r i} \Delta \delta_{i}, \quad i=2,3,4
\end{aligned}
$$

$$
\begin{aligned}
\Delta a_{y s t i} & =\frac{\mathrm{d} a_{y}}{\mathrm{~d} \alpha_{r i}}\left(\Delta \alpha_{r i}\right)+\frac{\mathrm{d} a_{y}}{\mathrm{~d} \alpha_{l i}}\left(\Delta \alpha_{l i}\right) \\
& =-\frac{2 F_{z o} P_{k y 1} k_{t i}\left(\frac{F_{z l i}+F_{z r i}}{F_{z o} P_{k y 2}}\right)}{m} \Delta \delta_{i}, \quad i=2,3,4 .
\end{aligned}
$$

The first front axle of the studied truck uses a single tire on both sides, but the other wheels use double tires. For accuracy, a factor $k_{t i}$ is introduced in the double tire model, where the sideslip angle $\alpha_{i}$ is the mean of the two tires. Assuming the longitudinal forces of tires are the same as the initial longitudinal forces $\left(F_{x r i, x l i}=F_{x r i_{0}, x l i_{0}}\right)$, from Eqs. (12) and (14), the ratios of yaw moment and lateral acceleration to tire sideslip angle can be shown as Eqs. (15) and (16), respectively. The extra yaw moment and lateral acceleration are shown in Eqs. (17) and (18), respectively, where $F_{z r i, z l i}$ is the calculated vertical tire force. From these equations, a larger $l_{r i}$ generates a larger extra yaw moment. A larger axle vertical force can generate a larger extra lateral acceleration. As the cargo weight increases, the vertical forces of the two rear axles becomes larger than that of the second axle. From the truck parameters, it is also clear that the fourth axle has a larger $l_{r i}$. Therefore, steering on the fourth axle has the best potential of vehicle stability control. From Eqs. (15) and (16), the variations of lateral acceleration and yaw moment respond oppositely during steering. The AS system generates an extra detrimental lateral acceleration during controlling. Thus, the absolute value of lateral acceleration is limited to $\pm 0.6 g$ based on experience. Eq. (19) shows the lateral acceleration of the truck with control, $\Delta a_{y s t i}$ is the lateral acceleration generated by AS, and $a_{y 0}$ is the initial acceleration. If $\left|a_{y a s}\right|$ is greater than $0.6 g$, the maximum or minimum extra lateral acceleration and extra yaw moment are presented in Eqs. (20) and (21), respectively. The maximum steering angle is indicated in Eq. (22):

$$
a_{y a s}=\Delta a_{y s t i}+a_{y 0}
$$

$$
\left\{\begin{array}{l}
\text { If }-0.6 g \leq a_{y a s} \leq 0.6 g, \\
\Delta a_{y s t i_{\max }, y s t i_{\min }}=\frac{2 F_{z o} P_{k y 1} k_{t i}}{m}\left(\frac{F_{z l i}+F_{z r i}}{F_{z 0} P_{k y 2}}\right) \Delta \delta_{i_{\max }, i_{\min }}, \\
\Delta a_{y s t i_{\max , \min }}= \pm(0.6 g)-a_{y 0}, \quad \text { else. }
\end{array}\right.
$$

$$
\begin{aligned}
& \Delta M_{z s t i_{\max }, z s t i_{\min }}=-m \Delta a_{y s t i_{\max }, y s t i_{\min }}\left(l_{i-1}-l_{v}\right), \\
& \left\{\begin{array}{l}
\text { If } a_{y a s}>0.6 g \text { or } a_{y a s}<-0.6 g, \\
\delta_{i_{\max , \min }}=\frac{-m\left(\Delta a_{y s t i_{\max , \min }}\right)}{\left(2 F_{z o} P_{k y 1} k_{t i}\left(\frac{F_{z l i}+F_{z r i}}{F_{z o} P_{k y 2}}\right)\right)}+\delta_{i 0}, \\
\delta_{i_{\max }}=8, \quad \delta_{i_{\min }}=-8, \quad \text { else. }
\end{array}\right.
\end{aligned}
$$




\subsection{Differential Braking}

Based on Kamm's Circle, braking can be classified into three different scenarios: The root of the quadratic summation of the braking force and lateral force is (1) smaller than, (2) equal to, and (3) larger than the radius of Kamm's Circle. When braking is applied on one of the wheels, its longitudinal force is identical to the braking force, $F_{x r i, x l i}=F_{b x l i, b x r i}$. Regarding other tires, $F_{x r i, x l i}$ is the initial longitudinal force $F_{x r i i_{0}, x l i_{0}}$. When the braking process falls into scenario 2, its lateral force can be calculated as Eq. (23):

$$
\begin{aligned}
& F_{y l i, y r i}=\sqrt{\left(F_{z l i, z r i} \mu\right)^{2}-\left(F_{b x l i, b x r i}\right)^{2}} \\
& =\sqrt{\left(F_{z l i, z r i} \mu\right)^{2}-\left(F_{x l i, x r i}\right)^{2},} \\
& \left\{\begin{array}{l}
\frac{\mathrm{d} M_{z}}{\mathrm{~d} F_{x r 1, x l 1}}= \pm \frac{H}{2}+\delta_{1} l_{v}, \\
\frac{\mathrm{d} M_{z}}{\mathrm{~d} F_{x r i, x l i}}= \pm \frac{H}{2}-\delta_{i}\left(l_{i-1}-l_{v}\right), \quad i=2,3,4,
\end{array}\right. \\
& A_{b r 1, b l 1}=\left( \pm \frac{H}{2}+l_{v} \delta_{1}\right), A_{b r i, b l i}=\left( \pm \frac{H}{2}-\left(l_{i-1}-l_{v}\right) \delta_{i}\right), \\
& B_{b r 1, b l 1}=\left( \pm \frac{H}{2} \delta_{1}-l_{v}\right), B_{b r i, b l i}=\left( \pm \frac{H}{2} \delta_{i}+\left(l_{i-1}-l_{v}\right)\right),
\end{aligned}
$$

$$
\begin{aligned}
& \left\{\begin{array}{c}
\frac{\mathrm{d} M_{z}}{\mathrm{~d} F_{x r 1, x l 1}}= \pm \frac{H}{2}\left(\frac{F_{x r 1, x l 1} \delta_{1}}{\sqrt{\left(F_{z r 1, z l 1} \mu\right)^{2}-F_{x r 1, x l 1}^{2}}}+1\right)+\cdots \\
l_{v}\left(\delta_{1}-\frac{F_{x r 1, x l 1}}{\sqrt{\left(F_{z r 1, z l 1} \mu\right)^{2}-F_{x r 1, x l 1}^{2}}}\right)=\left( \pm \frac{H}{2}+l_{v} \delta_{1}\right)+\cdots
\end{array}\right. \\
& +\left( \pm \frac{H}{2} \delta_{1}-l_{v}\right) \frac{F_{x r 1, x l 1}}{\sqrt{\left(F_{z r 1, z l 1} \mu\right)^{2}-F_{x r 1, x l 1}^{2}}}, \\
& \left\{\frac{\mathrm{d} M_{z}}{\mathrm{~d} F_{x r i, x l i}}= \pm \frac{H}{2}\left(\frac{F_{x r i, x l} \delta_{i}}{\sqrt{\left(F_{z r i, z l i} \mu\right)^{2}-F_{x r i, x l i}^{2}}}+1\right)-\cdots\right. \\
& -\left(l_{i-1}-l_{v}\right)\left(\delta_{i}-\frac{F_{x r i, x l i}}{\sqrt{\left(F_{z r i, z l i} \mu\right)^{2}-F_{x r i, x l i}^{2}}}\right) \\
& =\left( \pm \frac{H}{2}-\left(l_{i-1}-l_{v}\right) \delta_{i}\right)+\cdots
\end{aligned}
$$

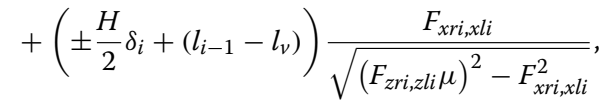

$$
\begin{aligned}
& \delta_{1} \geq 0, \quad \delta_{i} \geq 0, \quad i=2,3,4 .
\end{aligned}
$$

Assuming the steering angle is positive on the left side, for a braking process under scenario 1 , the variation of yaw moment with respect to the longitudinal force can be obtained using Eq. (24) based on Eq. (12). For a braking process under scenario 2, the speed of yaw moment can be described by Eq. (26).

Considering the ability of the air braking system and tires, the largest braking force is $-18587 \mathrm{~N}$. The largest longitudinal braking forces based on vertical tire force $\left(F_{x i_{z} \max x} x l i_{z \max }\right)$, and the largest longitudinal force with constant lateral force $\left(F_{x r i_{\text {max }}, x l i_{c \max }}\right)$ are as follows $(i=1,2,3,4)$ :

$$
\begin{aligned}
& F_{x r i_{\text {range }}, x l_{\text {range }}}=-18587 \mathrm{~N}, \quad F_{x r i_{z \max }, x l_{z \max }}=-F_{z r i, z l i} \mu, \\
& F_{x i_{c_{\text {max }}, x} x l_{c_{\text {max }}}}=-\sqrt{\left(F_{z r i, z l i} \mu\right)^{2}-\left(F_{y r i_{0}, y l l_{0}}\right)^{2}} .
\end{aligned}
$$

Eq. (27) is the integral equation of Eq. (26), which describes the yaw moment variation caused by braking under scenarios 1 and 2. $F_{x r i_{x}, x l i_{x}}$ is the largest longitudinal force under scenario 1 .

$$
\begin{aligned}
& \Delta M_{z b r i_{\max }, z b l i_{\max }} \\
& =q_{1 i} A_{b r i, b l i}\left(F_{x r i_{x}, x l i_{x}}-F_{x r i_{0}, x l i_{0}}\right)+\cdots \\
& q_{2 i}\left(\left(\begin{array}{l}
A_{b r i, b l i} F_{x r i_{\max }, x l i_{\max }}-\cdots \\
B_{b r i, b l i} \sqrt{\left(F_{z r i, z l i} \mu\right)^{2}-F_{x i_{\max }, x l i_{\max }}^{2}}
\end{array}\right)-\cdots\right. \\
& -\left(\begin{array}{l}
A_{b r i, b l i} F_{x r i_{x}, x l i_{x}}-\cdots \\
B_{b r i, b l i} \sqrt{\left(F_{z r i, z l i} \mu\right)^{2}-F_{x r i_{x}, x l i_{x}}^{2}}
\end{array}\right), \\
& \left\{\begin{array}{l}
F_{x r 1_{n p}, x l 1_{n p}}=\frac{-\left( \pm \frac{H}{2}+l_{v} \delta_{1}\right) F_{z r 1, z l 1} \mu}{\sqrt{\left( \pm \frac{H}{2}+l_{v} \delta_{1}\right)^{2}+\left( \pm \frac{H}{2} \delta_{1}-l_{v}\right)^{2}}}, \\
F_{x r i_{n p}, x l i_{n p}}= \\
\frac{-\left( \pm \frac{H}{2}-\left(l_{i-1}-l_{v}\right) \delta_{i}\right) F_{z r i, z l i} \mu}{\sqrt{\left[\left( \pm \frac{H}{2} \delta_{i}+\left(l_{i-1}-l_{v}\right)\right)^{2}+\cdots+\left( \pm \frac{H}{2}-\left(l_{i-1}-l_{v}\right) \delta_{i}\right)^{2}\right]}}, \\
i=2,3,4 .
\end{array}\right.
\end{aligned}
$$

From Eq. (26), the yaw moment rate has different null points as the vehicle structure parameters change. Therefore, the variation of yaw moment Eq. (27) will be different under different scenarios. The rule of changing when the forces of wheels are under scenario 2 is shown in Table 1 . The best braking force to generate the largest yaw moment on the left or right sides can be derived from Eq. (26). The fact that the equations are equal to zero means Eq. (27) has an extremum. If the equations are positive or negative, Eq. (27) is monotonic. In the table, condition a1 means Eq. (26) has a null point, condition a2 generates an undesired yaw moment, and condition a3 means the wheel can add a braking force as large as possible. Table 2 shows the best braking forces $F_{x r i_{\max }, x l i_{\max }}$ and parameters of Eq. (27) under different scenarios. $F_{x i_{n p}, x l_{n p}}$ from Eq. (28) 
denotes the braking force at the null point under scenario 2. Based on the parameters and steering angle in Eq. (27), the wheel condition is obtained from Table 1. Based on the initial forces and conditions from Table 1, the parameters and braking forces in Eq. (27) are needed to change as per Table 2 for generating the largest control yaw moment.

The extra yaw moment generated by the DB system is shown in Eq. (29). When a truck experiences slipping or drifting, it is very dangerous to apply braking on rear axles. Therefore, a rule for braking on the third and fourth axles is set to avoid the DB from deteriorating the instability of the vehicle under some special conditions. The lateral forces must be within the ranges of the tires. Eq. (30) can be obtained by the conservation of forces in Part 3 of the truck. In the equation, $\varsigma$ is a factor for rear amplification effect. The largest lateral force provided by the tire can be represented by the vertical force and friction coefficient. If the lateral force of Part 3 in Figure 1 is larger than the forces by the tires, the vehicle becomes unstable. Based on this idea and Eq. (30), Figure 5 is proposed as a decision logic for which wheel needs to be added for more braking force.

$$
\begin{aligned}
\Delta M_{z b r_{\max }, z b l_{\max }=} & \Delta M_{z b r 1_{\max }, z b l 1_{\max }}+\Delta M_{z b r 2_{\max }, z b l 2_{\max }}+\cdots \\
& +\Delta M_{z b r 3_{\max }, z b l 3_{\max }}+\Delta M_{z b r 4_{\max }, z b l 4_{\max }}
\end{aligned}
$$

$$
\left\{\begin{array}{l}
F_{y r 34}=\varsigma a_{y}\left(\frac{m_{c}}{2}+2 m_{a}\right)-\left[\mu\left(F_{z l 4}+F_{z l 3}\right)\right], \\
F_{y r 3}=\varsigma a_{y}\left(\frac{m_{c}}{2}+2 m_{a}\right)-\cdots \\
\quad-\left[\mu\left(F_{z l 4}+F_{z l 3}+F_{z r 4}\right)-F_{y r 4}\right], \\
F_{y r 4}=\varsigma a_{y}\left(\frac{m_{c}}{2}+2 m_{a}\right)-\cdots \\
\quad-\left[\mu\left(F_{z l 4}+F_{z l 3}+F_{z r 4}+F_{z r 3}\right)-F_{y r 4}-F_{y r 3}\right],
\end{array}\right.
$$

\subsection{Comparison}

Both the DB and AS systems affect the vehicle states by generating an extra yaw moment. Therefore, the effects of DB and AS can be compared by the variations of yaw moment and yaw rate, which can be calculated using Eqs. (21) and (29), respectively.

From Figure 6, the feasibility of this comparison method can be proved. The yaw moment is difficult to measure; therefore, the yaw angle rate is used for comparison. Assume the factor for transforming the extra yaw moment to the variation of yaw rate is $J_{m a}\left(J_{m a}=10000, \Delta \dot{\psi}=\Delta M_{z} / J_{m a}\right)$. Figure 6 shows the comparison under different conditions, where the solid lines are results from Eqs. (21) and (29). DB or AS operate to generate an opposite yaw moment after steering. The yaw rates in figures are the results at $0.5 \mathrm{~s}$ after DB or AS is applied. From the figures, it can be shown that the trends of Eqs. (21) and (29) are close to the real extra yaw moment; therefore, the comparison results can be used as references in rollover prevention and yaw stability control strategy. From the analysis and comparison, the steering angle is positive one the left side, while the yaw moment generated by AS or DB is negative on the right.

\section{Rollover Prevention and Yaw Movement Control}

Using one optimization process to determine the braking torques and steering angle of a multi-axle truck is complex. Moreover, introducing too many variables slows down the optimization process. A novel control strategy, as shown in Figure 7 , is proposed with several simple optimal calculations based on the analysis method discussed in Section 3. In this study, assume the roll angle, roll angle rate, yaw rate, and slip angle are acquired by sensors or observations such as those in Ref. [34]. The

\begin{tabular}{|c|c|c|}
\hline Conditions & $\leftarrow$ Right first wheel (if) & Left first wheel (if) \\
\hline a1 & $B_{b r 1}>0, A_{b r 1}>0, \delta_{i}>0$ & $B_{b / 1}<0, A_{b / 1}<0, \delta_{i} \geq 0$ \\
\hline a2 & Impossible under $\delta_{i} \geq 0$ & $B_{b / 1}<0, A_{b / 1} \geq 0, \delta_{i} \geq 0$ \\
\hline a3 & $B_{b r 1} \leq 0, A_{b r 1}>0, \delta_{i} \geq 0$ & Impossible under $\delta_{i} \geq 0$ \\
\hline a4 & Impossible under $\delta_{i} \geq 0$ & Impossible under $\delta_{i} \geq 0$ \\
\hline Conditions & $\leftarrow$ Right wheel $i=2,3,4$ (if) & Left wheel $i=2,3,4$ (if) \\
\hline a1 & $\begin{array}{l}\text { A) } I_{i-1}-I_{V}>0, B_{b r i}>0, A_{b r i}>0, \delta_{i}>0 \\
\text { B) } I_{i-1}-I_{V}<0, B_{b r i}>0, A_{b r i}>0, \delta_{i}>0 \\
\text { C) } I_{i-1}-I_{V}>0, B_{b r i}>0, A_{b r i}>0, \delta_{i}=0 \\
\text { D) } I_{i-1}-I_{V}=0, \delta_{i}>0\end{array}$ & $\begin{array}{l}\text { A) } I_{i-1}-I_{v}>0, B_{b l i}<0, A_{b l i}<0, \delta_{i}>0 \\
\text { B) } I_{i-1}-I_{V}<0, B_{b l i}<0, A_{b l i}<0, \delta_{i}>0 \\
\text { C) } I_{i-1}-I_{v}<0, B_{b l i}<0, A_{b l i}<0, \delta_{i}=0 \\
\text { D) } I_{i-1}-I_{v}=0, \delta_{i}>0\end{array}$ \\
\hline a2 & $I_{i-1}-I_{v}>0, B_{b r i}>0, A_{b r i}<0, \delta_{i}>0$ & $I_{i-1}-I_{v}<0 B_{b l i}<0 A_{b l i}>0 \delta_{i}>0$ \\
\hline a3 & $\begin{array}{l}\text { A) } I_{i-1}-I_{v}<0, B_{b r i} \leq 0, A_{b r i}>0, \delta_{i}>0 \\
\text { B) } I_{i-1}-I_{v}<0, B_{b r i}<0, A_{b r i}>0, \delta_{i}=0 \\
\text { C) } I_{i-1}-I_{v}=0, \delta_{i}=0\end{array}$ & $\begin{array}{l}\text { A) } I_{i-1}-I_{V}>0, B_{b l i} \geq 0, A_{b l i}<0, \delta_{i}>0 \\
\text { B) } I_{i-1}-I_{V}>0, B_{b l i}>0, A_{b l i}<0, \delta_{i}=0 \\
\text { C) } I_{i-1}-I_{V}=0, \delta_{i}=0\end{array}$ \\
\hline a4 & $B_{b r i}=0, A_{b r i}=0$ (Cannot use this wheel to brake) & $B_{b l i}=0, A_{b l i}=0$ (Cannot use this wheel to brake) \\
\hline
\end{tabular}
corresponding estimation algorithms for unmeasurable

Table 1 Rule of changing under scenario 2 
Table 2 Best braking forces $F_{x i_{\max }, x i_{\text {max }}}$ and parameters of Eq. (27)

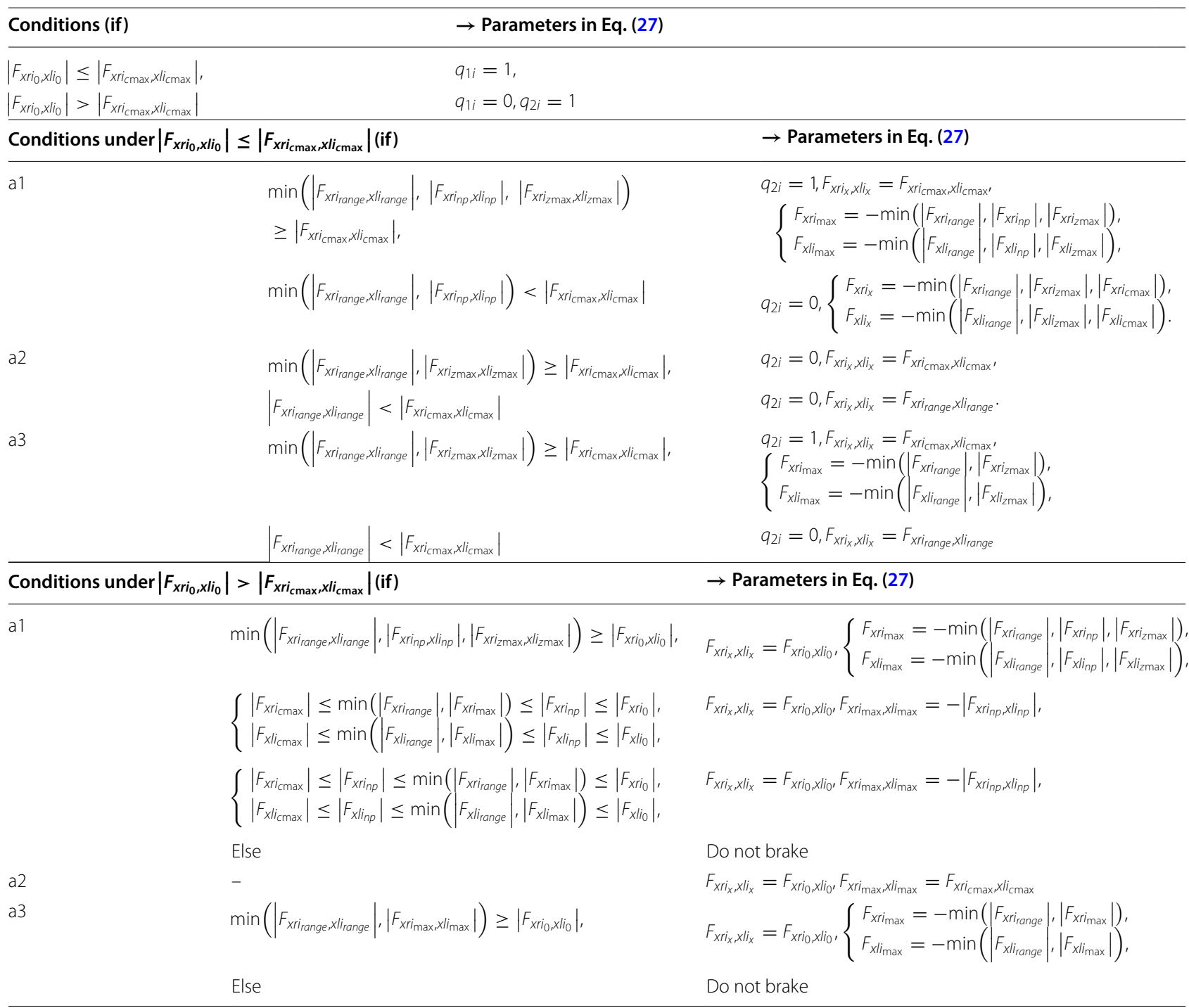

variables will be designed in future work for real applications. Based on the lateral load transfer ration (LTR) and yaw rate judgment, the strategy determines whether to activate the control system. When a control action for preventing the accident is required, the analysis module and sliding mode controller are activated. Based on the analysis and outputs of the sliding mode controller, seven optimization subsystems are designed to determine the final control outputs and to send to the local controllers of the braking system and the active steering system. Each optimization subsystem will be determined whether it needs to be activated. The DB system controls all wheels of the truck, and the AS system only controls the fourth axle.
LTR and ideal yaw rate in the control strategy are used as indexes to indicate the rollover and yaw stability accidents. LTR is a widely used index for rollover warning or rollover prevention, based on Eqs. (1)-(10). LTR in this research can be defined as Eq. (31). The LTR threshold is set as 0.55 . The details of gains are in Appendix (Eqs. 51-53).

$$
L T R=\left|\frac{\left(F_{z r}-F_{z l}\right)}{\left(F_{z r}+F_{z l}\right)}\right|=\left|K_{a y} a_{y}+K_{\varphi} \varphi+K_{\dot{\varphi}} \dot{\varphi}\right| .
$$

The ideal yaw rate is calculated by Eq. (32). Once the deviation between the ideal and real yaw rate goes beyond a designed range ( $\pm 0.02 \mathrm{rad})$, indicating the vehicle is in the oversteer or understeer situation, the controller starts to work. 


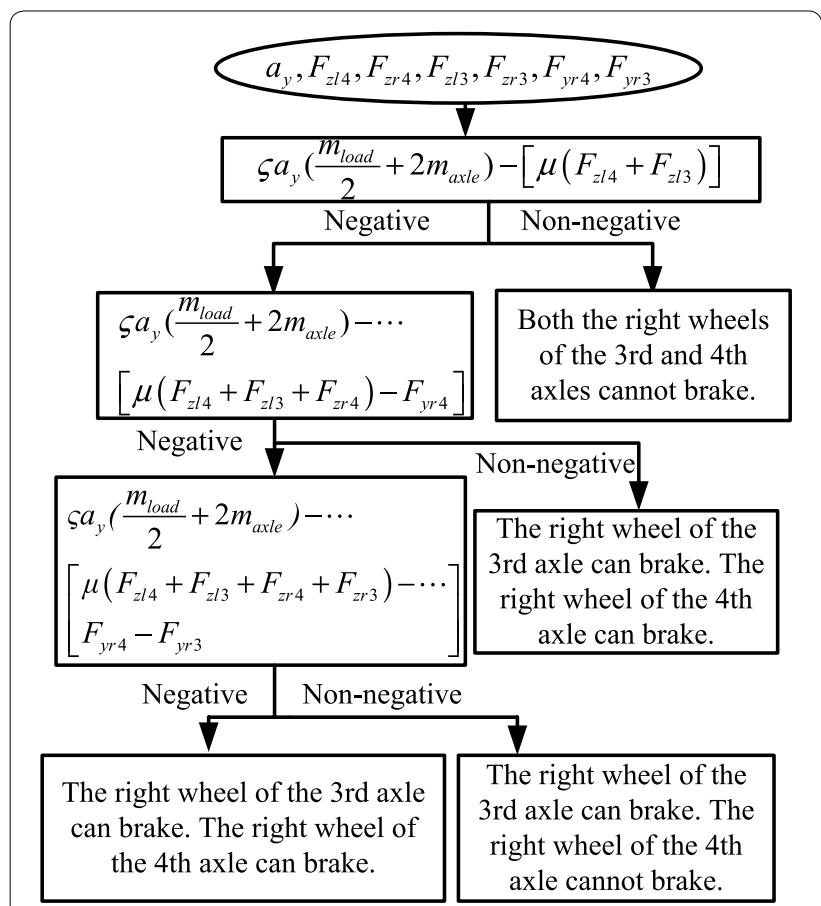

Figure 5 Logic of braking actions

$$
\dot{\psi}_{d}=\frac{v_{x}}{\left(l_{\nu}+l_{r 3}\right)\left(1+K_{\dot{\psi}} v_{x}^{2}\right)} \delta_{1}, \quad K_{\psi}=0.0025 .
$$

A sliding mode control algorithm is designed because of its robustness [35], usually designed in two steps. The first step is to design a sliding surface, and the second step is to design a control law, which drives or keeps the states to the designed sliding manifold [36]. The proposed controller is designed based on a discrete sliding mode control. A vehicle model including roll angle rate, roll angle, and yaw rate is described as Eq. (33):

$$
\left\{\begin{aligned}
J_{z} \ddot{\psi} & =M_{z s}, \\
J_{x} \ddot{\varphi} & =F_{y s} h+m_{s} g h \varphi-K \varphi-C \dot{\varphi} .
\end{aligned}\right.
$$

The discrete model is described as

$$
\left\{\begin{array}{l}
x(k+1)=A x(k)+B u(k) \\
y(k)=C x(k)+D u(k)
\end{array}\right.
$$

The details in Eq. (34) are shown in Table 3.

The sliding surface is defined as

$$
S(k)=E\left([\dot{\psi}(k) L T R(k)]^{\mathrm{T}}-d(k)\right),
$$

where $E=\left[\begin{array}{cc}100 & 0 \\ 0 & 1\end{array}\right]$.
The target $d$ is different under different conditions and is shown in Table 4.

The reaching law can be described as follows:

$$
S(k+1)=k_{s} S(k)-\left[\begin{array}{c}
k_{s m 1} \operatorname{sat}\left(S_{1}(k)\right) \\
k_{s m 2} \operatorname{sat}\left(S_{2}(k)\right)
\end{array}\right],
$$

where

$$
\operatorname{sat}(S(k))= \begin{cases}a, & \text { if }|a| \leq 1, \\ \operatorname{sgn}(S(k)), & \text { else. }\end{cases}
$$

$k_{s}=\left[\begin{array}{cc}0.9 & 0 \\ 0 & 0.5\end{array}\right], \quad k_{s m 1}=0.001, \quad k_{s m 2}=0.001, \quad a=\frac{S(k)}{\Theta}$,

$\Theta_{1}=0.025, \Theta_{2}=0.05$.

The sliding mode control law is derived as $u_{s}(k)$ :

$$
\begin{aligned}
& u_{s}(k)=u_{s 1}(k)+u_{s 2}(k), \\
& \left\{\begin{array}{c}
u_{s 1}(k)=-(E(C B+D))^{-1} \\
\times(E(C(A x(k))))+(E(C B+D))^{-1} E d(k), \\
u_{s 2}(k)=(E(C B+D))^{-1} \\
\times\left(k_{s} S(k)-\left[\begin{array}{l}
k_{s m 1} \operatorname{sat}\left(S_{1}(k)\right) \\
k_{s m 2} \operatorname{sat}\left(S_{2}(k)\right)
\end{array}\right]\right) .
\end{array}\right.
\end{aligned}
$$

The outputs of the sliding mode control are the desired yaw moment and lateral force of the truck. Eq. (39) presents the deviations of the desired yaw moment and lateral force between real yaw moment and lateral force. From the analysis in Section 3, the maximum yaw moment and maximum braking force of each tire can be calculated. The results can be used for evaluating the effects of each stability control method. In general, the wheel with more potentials should take more responsibilities. Therefore, the entire lateral force and yaw moment can be separated by reasonable gains, which are described by the maximum yaw moment changes of different wheels. The gains of yaw moment and force distribution are defined as indicated in Eq. (40). When the extra yaw moment is positive, the gains of the right side are zero. Otherwise, the gains of the left side are zero. If the gain of the wheel is zero, its optimization will not be activated.

$$
\left\{\begin{aligned}
\Delta F_{y s}(k) & =F_{y s}(k)-m a_{y}(k), \\
\Delta M_{z s}(k) & =M_{z s}(k)-J_{z}\left(\frac{\dot{\psi}(k)-\dot{\psi}(k-1)}{T}\right),
\end{aligned}\right.
$$

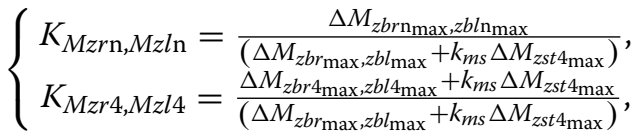

$$
\begin{aligned}
& n=1,2,3, \quad k_{m s}=0.001 \text {, }
\end{aligned}
$$




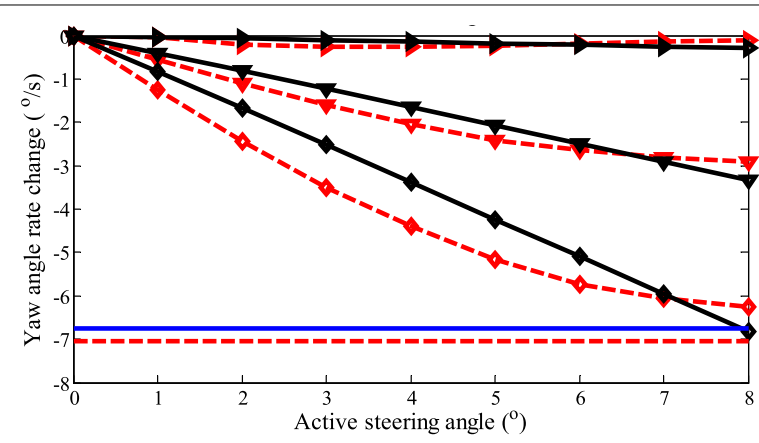

a $90 \mathrm{~km} / \mathrm{h}$ step steering input $40^{\circ}$

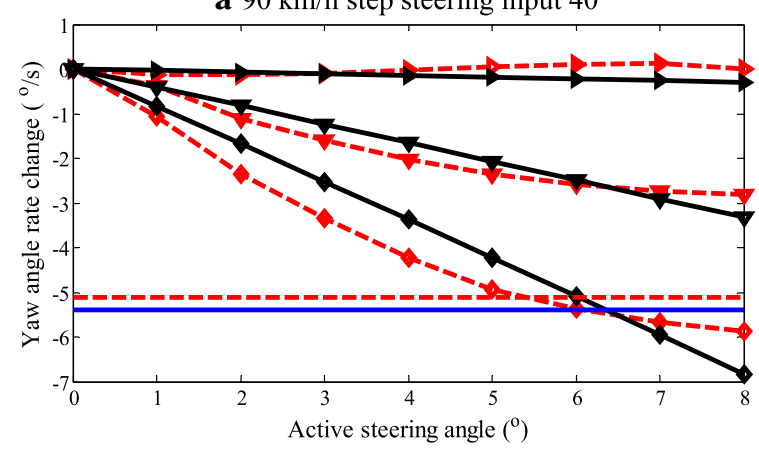

- Real maximum yaw angle rate change generated by AS (2nd axle) - - Real maximum yaw angle rate change generated by AS (3rd axle) - - Real maximum yaw angle rate change generated by AS (4th axle) $\rightarrow$ Calculated maximum yaw angle rate change generated by AS (2nd axle) - Calculated maximum yaw angle rate change generated by AS (3rd axle) $\checkmark$ Calculated maximum yaw angle rate change generated by AS (4th axle) Calculated maximum yaw angle rate change generated by DB - - - Real maximum yaw angle rate change generated by DB

b $90 \mathrm{~km} / \mathrm{h}$ step steering input $80^{\circ}$

Figure 6 Comparison of AS and DB under different work

$$
\left\{\begin{aligned}
\Delta F_{y s r i, y s l i}(k) & =K_{M z r i, M z l i} \Delta F_{y s}(k), \\
\Delta M_{z s r i, z s l i}(k) & =K_{M z r i, M z l i} \Delta M_{z s}(k) .
\end{aligned}\right.
$$

$K_{M z r i, M z l i}$ is introduced as the weight of DB and AS. The smaller $K_{M z r i, M z l i}$ is, the lesser is the involvement of integrated control. Zero $K_{M z r i, M z l i}$ means the wheel cannot improve the stability by braking and steering. To

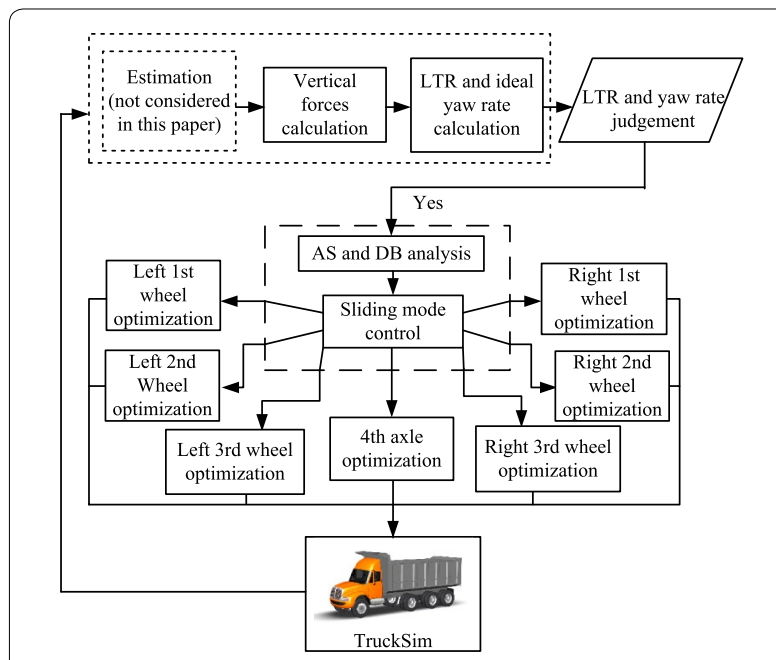

Figure 7 Integrated control strategy design for four-axle truck

$\Delta M_{z b r 4_{\max }, z b l 4_{\max }}=0$ and $k_{m s}=1$. This means only steering system is active during control in $K_{M z r 4, M z l 4}$. In the DB system, $\Delta M_{z s t 4_{\max }}=0$, which means only braking system works in Eq. (40). Based on the allocation gains, the lateral force and yaw moment change caused by each wheel can be described by Eq. (41). After the deviations of desired lateral force and yaw moment of each wheel are known, an optimal problem occurs. To each controlled wheel, the lateral forces and yaw moment should be close to ideal. Therefore, the deviations represented as Eqs. (43) and (44) should be as close as zero. The objective function of the optimization is presented as Eq. (42). In the equation, $K_{J 1}$ and $K_{J 2}$ are weights of deviations:

$$
J_{\min r i, \min l i}(x)=K_{J 1}\left(\Delta M_{z J r i, z J l i}(x)\right)^{2}+K_{J 2}\left(\Delta F_{y J r i, y J l i}(x)\right)^{2},
$$

where $i=1,2,3,4, K_{J 1}=1, K_{J 2}=1$.

In Eq. (45), $F_{x r i, x l i}$ and $F_{y r i, y l i}$ are the longitudinal forces and lateral forces at the moment, respectively, based on the vertical forces of tires, slip angles, and slip ratios searched from maps (shown in Appendix Figure 17, maps are from TruckSim). $F_{x d r i, x d l i}$ is the desired braking force.

$$
\left\{\begin{array}{l}
\Delta M_{z J r 1, z J l 1}=\Delta M_{z s r 1, z s l 1}-\cdots-\left[\left(F_{O Y 1} l_{v}\right)-\left(F_{Y 1} l_{v}\right)+\cdots+\frac{H}{2}\left(F_{O X R 1}-F_{O X L 1}\right)-\frac{H}{2}\left(F_{X R 1}-F_{X L 1}\right)\right], \\
\Delta M_{z J r i, z J l i}=\Delta M_{z s r i, z s l i}-\cdots-\left[\left(-F_{O Y i} l_{h i-1}\right)-\left(-F_{Y i} l_{h i-1}\right)+\cdots+\frac{H}{2}\left(F_{O X R i}-F_{O X L i}\right)-\frac{H}{2}\left(F_{X R i}-F_{X L i}\right)\right], \quad i=2,3,4,
\end{array}\right.
$$

compare the differences between AS, DB, and proposed integrated control system, a single AS system and a single DB system are also given based on the desired yaw moment and lateral force distribution. In the AS system

$$
\Delta F_{y J r i, y J l i}=\Delta F_{y s r i, y s l i}-\left(F_{O Y i}\right)
$$


Table 3 Details of Eq. (34)

\section{Details of Eq. (34)}

$x(k)=\left[\begin{array}{lll}\dot{\psi}(k) & \dot{\varphi}(k) & \varphi(k)\end{array}\right]^{\top}, u(k)=\left[\begin{array}{ll}M_{z s} & F_{y s}\end{array}\right]^{\top}$,

$y(k)=[\dot{\psi}(k) L T R(k)]^{\top}$,

$A=\left[\begin{array}{ccc}1 & 0 & 0 \\ 0 & 1-\frac{C T}{J_{x}} & -\frac{T\left(K-g h m_{s}\right)}{J_{x}} \\ 0 & T & 1\end{array}\right]$,

$B=\left[\begin{array}{cc}\frac{1}{J_{z}} T & 0 \\ 0 & \frac{h}{J_{x}} T \\ 0 & 0\end{array}\right], C=\left[\begin{array}{ccc}1 & 0 & 0 \\ 0 & K_{\dot{\varphi}} & K_{\varphi}\end{array}\right], D=\left[\begin{array}{cc}0 & 0 \\ 0 & \frac{K_{a y}}{m}\end{array}\right]$

$$
\begin{aligned}
& \left\{\begin{array}{l}
F_{O X R i, O X L i}=-F_{y d r i, y d l i} \sin \delta_{i}+F_{x d r i, x d l i} \cos \delta_{i}, \\
F_{O Y R i, O Y L i}=F_{x d r i, x d l i} \sin \delta_{i}+F_{y d r i, y d l i} \cos \delta_{i}, \\
F_{X R i, X L i}=-F_{y r i, y l i} \sin \delta_{i}+F_{x r i, x l i} \cos \delta_{i}, \\
F_{Y R i, Y L i}=F_{x r i, x l i} \sin \delta_{i}+F_{y r i, y l i} \cos \delta_{i},
\end{array}\right. \\
& \left\{\begin{array}{r}
F_{O y i}=\left(F_{O y l i}+F_{O y r i}\right), \\
F_{Y i}=\left(F_{Y R i}+F_{Y L i}\right), \quad i=1,2,3,4,3,4
\end{array}\right.
\end{aligned}
$$

In Eq. (42) when the brake is on the first, second, or third axle, except for the fourth axle $(i=1,2,3)$, or under the condition that only DB system is working on the truck $(i=1,2,3,4)$, the optimization settings are

$$
\begin{aligned}
& x=x_{1}, \quad x_{1}=F_{x d r i, x d l i}, \\
& F_{y d r i, y d l i}=\left\{\begin{array}{l}
\text { If } F_{y r i, y l i}^{2}+F_{y r i, y l i}^{2}=\left(F_{z r i, z l i} \mu\right)^{2}, \\
\operatorname{sgn}\left(\alpha_{r i, l i}\right) \sqrt{\left(F_{z r i, z l i} \mu\right)^{2}-\left(x_{1}\right)^{2}} \\
\text { if } F_{y r i, y l i}^{2}+F_{y r i, y l i}^{2}<\left(F_{z r i, z l i} \mu\right)^{2}, \\
F_{y d r i, y d l i}=F_{y r i, y l i}, \\
\text { else } F_{y d r i, y d l i}=0 .
\end{array}\right.
\end{aligned}
$$

In the integrated control system, when both DB and AS are activated on the fourth axle in Eq. (42),

$$
\begin{aligned}
& F_{y d r 4, y d l 4}=\left\{\begin{array}{l}
\text { If } F_{y r 4, y l 4}^{2}+F_{y r 4, y l 4}^{2}=\left(F_{z r 4, z l 4} \mu\right)^{2}, \\
\operatorname{sgn}\left(\alpha_{r 4, l 4}\right) \sqrt{\left(F_{z r 4, z l 4} \mu\right)^{2}-\left(x_{1}\right)^{2}} \\
\text { if } F_{y r 4, y l 4}^{2}+F_{y r 4, y l 4}^{2}<\left(F_{z r 4, z l 4} \mu\right)^{2}, \\
F_{y d r 4, y d l 4}=F_{y r 4, y l 4}, \\
\text { else } F_{y d r 4, y d l 4}=0,
\end{array}\right. \\
& x=\left[x_{1}, x_{2}\right], \quad x_{1}=F_{x d r 4, x d l 4}, \quad x_{2}=\delta_{4} .
\end{aligned}
$$

When only the AS control system is activated on the fourth axle, the optimization settings in Eq. (42) are

$$
x=x_{1}, \quad x_{1}=\delta_{4}, \quad F_{y d r 4, y d l 4}=F_{y r 4, y l 4} .
$$

The limitation of braking forces on each wheel should be within the braking force limits from Table 2. $\Delta M_{z J r i, z J l i}$ and $\Delta F_{y J r i, y J l i}$ are also limited for the optimization to be more accurate and faster. The limitation of these wheels controlled only by the DB system are

$$
\begin{aligned}
\text { limit 1: } & F_{x d r i, x d l i}<0, \quad F_{x r i_{\max }, x l i_{\max }}-F_{x d r i, x d l i} \leq 0, \\
& \left|\Delta M_{z J r i, z J l i}(x)\right| \leq 25, \quad\left|\Delta F_{y J r i, y J l i}(x)\right| \leq 10 .
\end{aligned}
$$

For the fourth axle, besides the limitations in limit 1, the steering angle should also be limited by Eq. (23). To keep the tires in the linear area, the absolute slip angles of tires are limited under $10^{\circ}$. The limitation of the fourth axle wheels is given in limit 2 .

$$
\begin{aligned}
\text { limit 2: } & F_{x d r 4, x d l 4} \leq 0, F_{x r 4_{\max }, x l 4_{\max }} \leq F_{x d r 4, x d l 4}, \delta_{\min } \leq \delta_{4} \leq \delta_{\max } \\
& \left|\Delta M_{z J r 4, z l 4}(x)\right| \leq 25, \quad\left|\Delta F_{y J r 4, y J l 4}(x)\right| \leq 10,\left|\alpha_{4}\right| \leq 10 .
\end{aligned}
$$

If there is only AS system on the truck, the limitation will be

$$
\begin{aligned}
& \text { limit 3: } \quad \delta_{\min } \leq \delta_{4} \leq \delta_{\max }, \quad\left|\alpha_{4}\right| \leq 10 \\
& \quad\left|\Delta M_{z J r 4, z J l 4}(x)\right| \leq 25, \quad\left|\Delta F_{y J r 4, y J l 4}(x)\right| \leq 10 .
\end{aligned}
$$

With the vertical force, the desired braking force can be transformed to the desired slip ratio based on the maps (in Appendix Figure 17). The slip ratio of the tire is limited under 0.15 , which makes the tire stay in the linear area. The longitudinal slip ratio is realized by the braking

Table 4 Target $\boldsymbol{d}$ under different conditions

\begin{tabular}{ll}
\hline Condition & $\boldsymbol{d}(\boldsymbol{k})$ \\
\hline$L T R \geq 0.55$ only & $d(k)=\left[\dot{\psi}(k) \operatorname{sgn}\left(a_{y}\right) L T R_{d}(k)\right]^{\top}, L T R_{d}=0.55$, \\
$\left|\dot{\psi}-\dot{\psi}_{d}\right| \geq 1.15^{\circ} \approx 0.02$ rad only & $d(k)=\left[\dot{\psi}_{d}(k) \operatorname{sgn}\left(a_{y}\right) L T R(k)\right]^{\top}$, \\
$L T R \geq 0.55$ and $\left|\dot{\psi}-\dot{\psi}_{d}\right| \geq 1.15^{\circ}$ & $d(k)=\left[\dot{\psi}_{d}(k) \operatorname{sgn}\left(a_{y}\right) L T R_{d}(k)\right]^{\top}, L T R_{d}=0.55$. \\
\hline
\end{tabular}


pressure calculated by a simple sliding mode control. Eq. (47) shows the wheel model for sliding mode controller. The simple sliding mode control is shown in Eq. (48) for calculating the desired braking torque. Based on the braking torque, the air pressure in braking system is obtained finally from Eq. (49). The sliding mode control reach law is $S_{b s r i, b s l i}=C_{b}\left(\kappa_{r i, l i}-\kappa_{d r i, d l i}\right)$, where $\kappa_{r i, l i}$ is the slip ratio and $\kappa_{d r i, d l i}$ is the desired slip ratio of the $i$ th left or right wheel. When $\left|\kappa_{r i, l i}-\kappa_{d r i, d l i}\right| \leq 0.001$, the sliding mode control stops. The existences of these sliding mode controls are certified in Appendix (Eqs. 54-60).

$$
\begin{aligned}
& J_{\text {ytire }} \dot{\omega}=r F_{x r i, x l i}+M_{b r i, b l i}, \\
& M_{b r i, b l i}=-C_{b}^{-1} A_{b}^{-1} T^{-1}\left(\begin{array}{l}
k_{b s} S_{b s r i, b s l i}-\cdots \\
-k_{b s m} \operatorname{sgn}\left(S_{b s r i, b s l i}\right)-\cdots \\
-C_{b} A_{b} \operatorname{Tr} F_{x r i, x l i}-S_{b s r i, b s l i}
\end{array}\right),
\end{aligned}
$$

$$
P_{b r i, b l i}=\frac{0.665}{10000} M_{b r i, b l i}+0.035
$$

In Eq. (48), $\quad C_{b}=1, \quad k_{b s}=0.8, \quad k_{b s m}=0.001$, $A_{b}=\left|\frac{r}{v_{x} J_{\text {ytire }}}\right|, i=1,2,3,4$.

\section{Analysis of Stability Control Algorithm}

To test the effectiveness of the proposed control system, TruckSim-Matlab Simulink cosimulation is conducted. TruckSim develops the truck model, while Matlab Simulink develops the control system, as shown in Figure 8. The truck runs under different velocities with a designed steering input, as shown in Figure 9. The coefficient of friction is 0.85 and the cargo weight is $5000 \mathrm{~kg}$.

To find the best steering speed, $5 \% \mathrm{~s}, 10^{\circ} / \mathrm{s}, 20^{\circ} / \mathrm{s}, 40^{\circ} / \mathrm{s}$, and $80 \%$ are used and their control performances are compared. The driver inputs a $180^{\circ}$ step steer under 90 $\mathrm{km} / \mathrm{h}$ (LTR is larger than 0.55 without control), the mean and mean variances of deviation (LTR to 0.55 ) with the AS control system under different steering speeds are

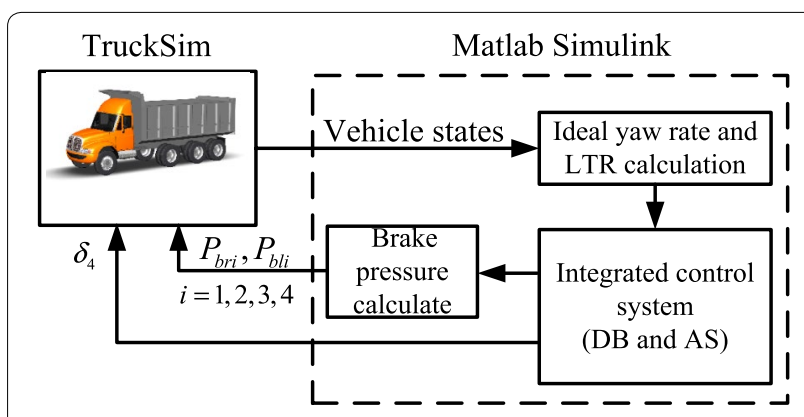

Figure 8 Simulation flowchart of TruckSim-Matlab Simulink cosimulation

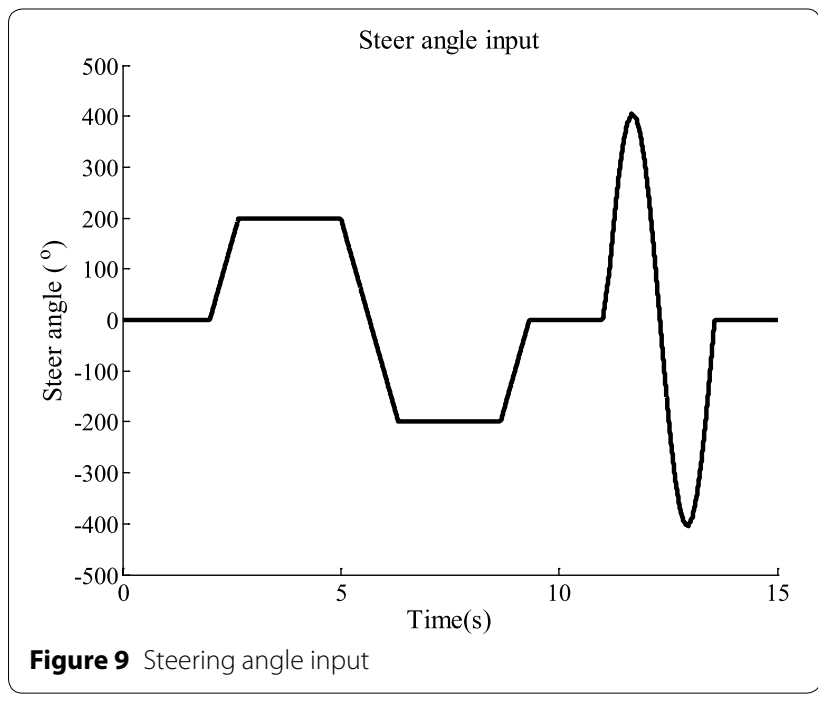

shown in Table 5 . As the steering speed increases, the LTR value oscillation becomes larger. However, if the steering variation is too small, the vehicle cannot be controlled back to steady. The AS system with $5 \%$ s and $10^{\circ} / \mathrm{s}$ steering variation cannot prevent the rollover accident. Therefore, the best steering variation of AS is $20 \%$ s.

Figures 10 and 11 show the LTR and yaw rate of the four-axle truck with integrated control system under different velocities. It is clear from Figure 11 that without the control system, the truck will rollover completely at $3.278 \mathrm{~s}$, whereas with the integrated control system the vehicle goes through without rollover. The real yaw rate with integrated controller follows the ideal yaw rate very well, and the LTR is controlled within or back to 0.55 quickly.

Figures 12 and 13 show the comparisons between single control methods, integrated control strategy, and system without control. The control system outputs such as braking pressures and fourth axle steering angle under $80 \mathrm{~km} / \mathrm{h}$ are given as Figure 18 (Appendix). Figure 12 shows the LTR under different conditions, where the truck without control rollovers at $3.6 \mathrm{~s}$ under $100 \mathrm{~km} / \mathrm{h}$. The DB system controls the rollover more smoothly, but the action speed is slower than AS. On the other hand, the AS system responds more quickly, but the LTR is still fluctuating. Since the DB slows the vehicle down, the more the DB system is working and the smaller is the LTR. Under a high velocity $(100 \mathrm{~km} / \mathrm{h}$ in Figure 12) with a large steering input, as indicated in Figure 9, the AS system cannot prevent rollover and the truck controlled by AS will rollover at $13.13 \mathrm{~s}$, making the DB system more effective. From the figures, the proposed integrated controller combines both DB and AS; thus, the LTR can be controlled as quickly as AS and as smoothly 
Table 5 LTR analysis under different steering speeds

\begin{tabular}{lll}
\hline AS speed $(\%)$ & Mean $($ LTR) & $\begin{array}{l}\text { Mean } \\
\text { variance } \\
\text { (LTR) }\end{array}$ \\
\hline 5 & 0.0355 & 0.0006 \\
10 & 0.0319 & 0.3028 \\
20 & 0.0435 & 0.3030 \\
40 & 0.0496 & 0.3035 \\
80 & 0.0514 & 0.3037 \\
\hline
\end{tabular}

as DB. Figure 13 shows the yaw rate under different conditions with different control system. Similarly, the truck with the DB system controls the truck smoothly, and the AS system responds more quickly than the DB system. Therefore, the performance of integrated control system is much better than that of DB or AS. The truck (cargo weight $5000 \mathrm{~kg}$ ) with proposed control system can keep away from rollover under $150 \mathrm{~km} / \mathrm{h}$ when the steering angle input is as per Figure 9, whereas the maximum velocity of the truck without control is just $89 \mathrm{~km} / \mathrm{h}$, the integrated control system can improve $68 \%$ of the safe velocity (DB 16.9\%, AS 12.4\%).
To verify the robustness of the proposed control system, the friction coefficients of the road are changed to 0.3 and 0.6. The steering input is a $200^{\circ}$ step input and the steering operation lasts for $0.66 \mathrm{~s}$. On a low friction road, the truck does not rollover, but the yaw stability becomes the main problem. Figure 14 shows the control performances under $70 \mathrm{~km} / \mathrm{h}$ on roads with 0.3 and 0.6 friction coefficients. The proposed integrated control system also works well under low friction road. Figure 15 shows the performances of integrated control system under 70 $\mathrm{km} / \mathrm{h}$ and $80 \mathrm{~km} / \mathrm{h}$ with $20000 \mathrm{~kg}$ cargo weight on high friction road (road friction coefficient 0.85 ); the steering input is as shown in Figure 9. The proposed integrated control system can also keep the truck from rollover. In Figure 15(b), the truck without control will rollover at $13.64 \mathrm{~s}$ under $80 \mathrm{~km} / \mathrm{h}$, but the proposed control system can keep the truck from rollover.

The simulation results demonstrate that the proposed integrated controller outperforms the DB or AS in terms of vehicle stability. The integrated control system combines the advantages of both DB and AS, thus improving the disadvantages of DB and AS. The proposed control system presents a good performance even under high velocities with a large steering angle input. In addition,

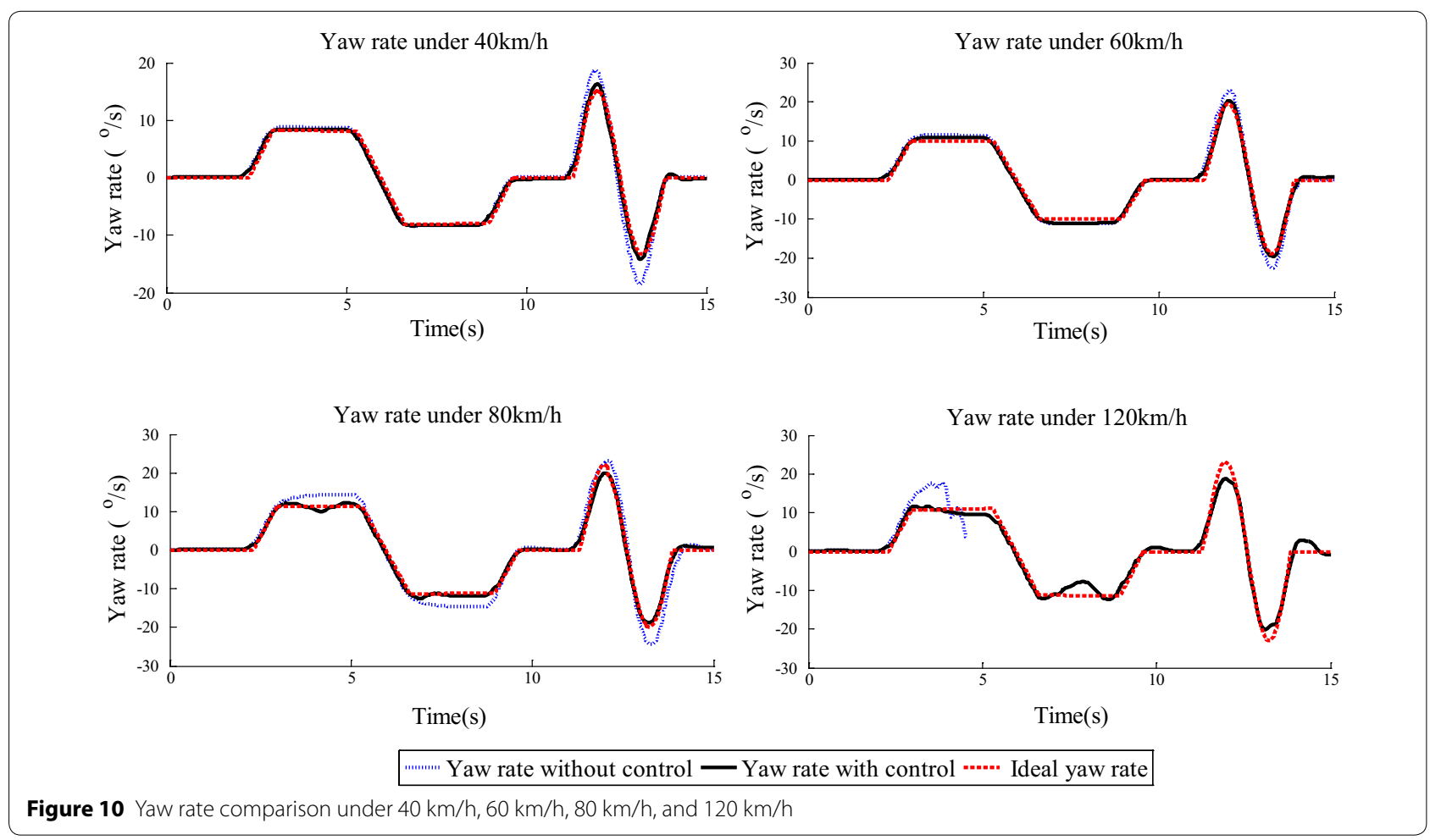



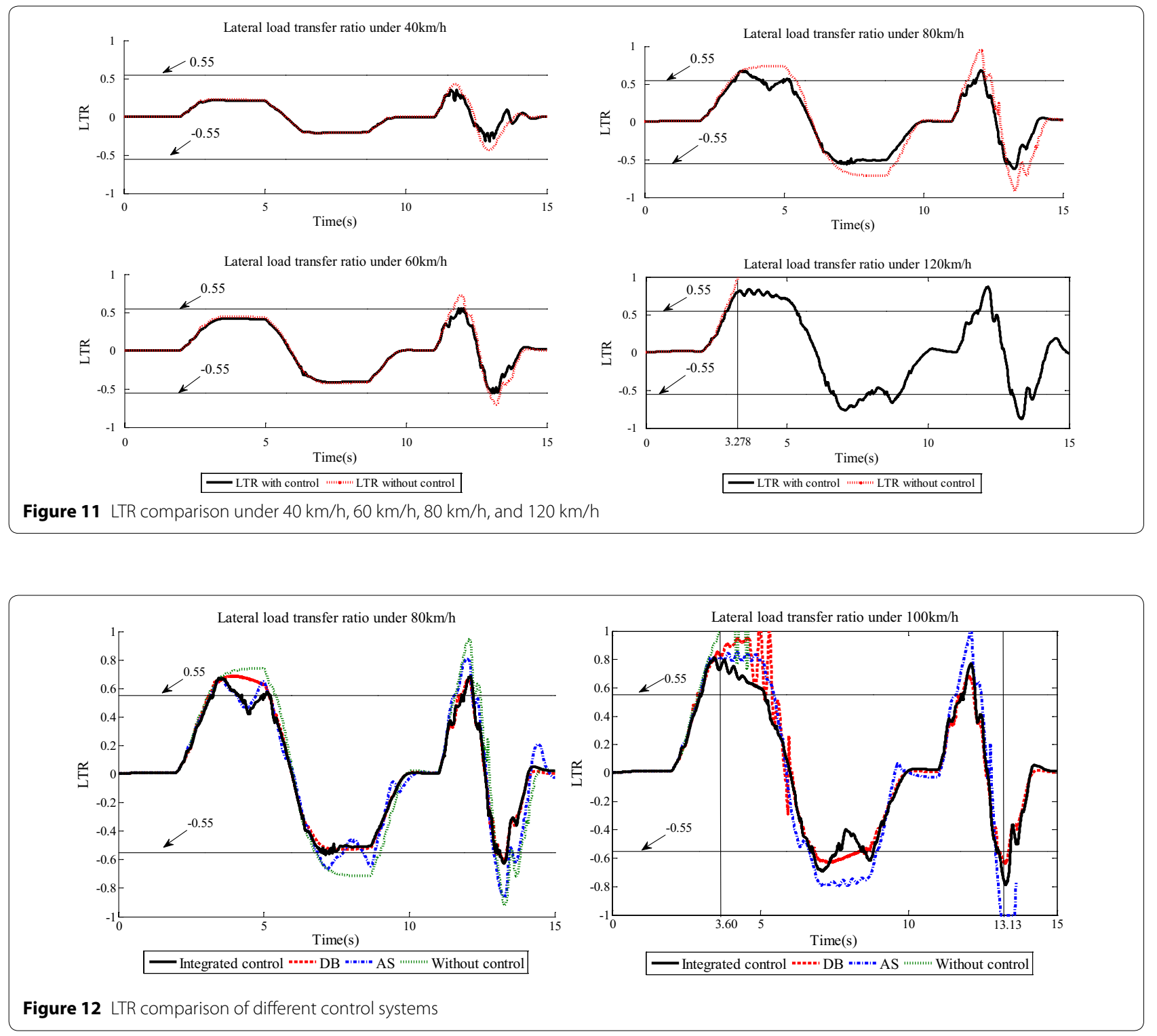

the proposed integrated control system can work well on low friction or different loads. From Figures 12 and 13, the integrated control system can unfold the advantages of both AS and DB simultaneously.

\section{Conclusions}

This paper proposed a novel integrated control system to improve the yaw and lateral stability for a four-axle truck. The proposed control system has a good performance in the multi-axle truck stability control. It has better control performance than DB or AS individually. First, a novel method was proposed to calculate the vertical forces of tires on four axles. Then, the analysis was presented based on the extra yaw moments generated by these two control systems. The effects and potentials of DB and AS were analyzed and compared according to how much extra yaw moment they can generate. The comparison results are transformed into gains for $\mathrm{DB}$ and $\mathrm{AS}$ coordination. In this way, the control system is more robust. Moreover, DB and AS can work simultaneously and efficiently. From the control results, the control system can unfold the characteristics of both DB and AS. The response is faster because distinct optimization is much more efficient and easier for calculation, and there is no expert system in the controller. From the analysis, the following conclusion can also be drawn.

For differential braking control: (1) In general, to prevent rollover or oversteer accidents, braking on outside wheels on axles in front of the CG point can generate a larger extra yaw moment than on rear axles. (2) To 

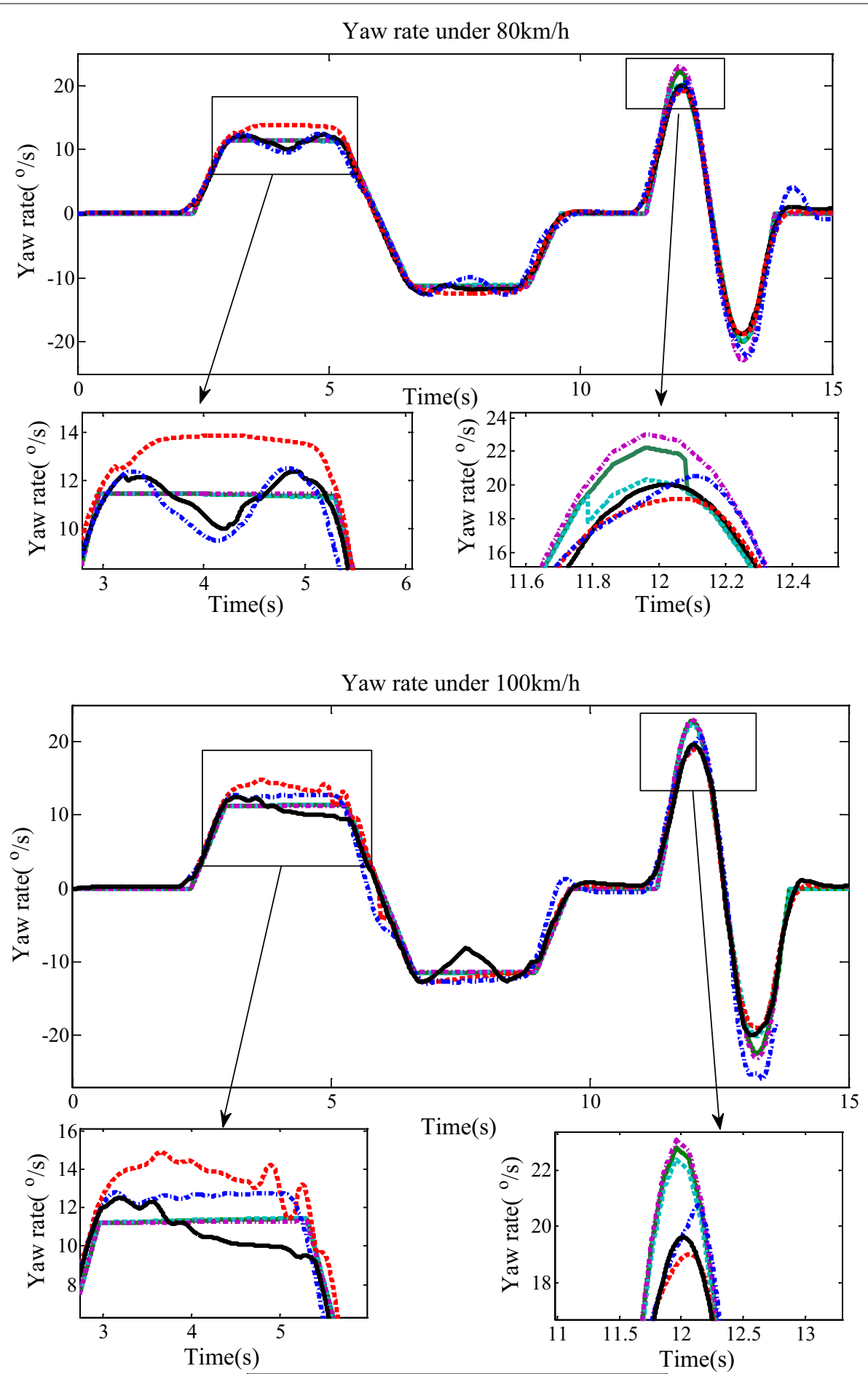

Ideal yaw rate with integrated control

"n=" Ideal yaw rate with DB

Ideal yaw rate with AS

..... Yaw rate with DB

-... Yaw rate with AS

- Yaw rate with integrated control

Figure 13 Yaw rate comparison of different control systems 


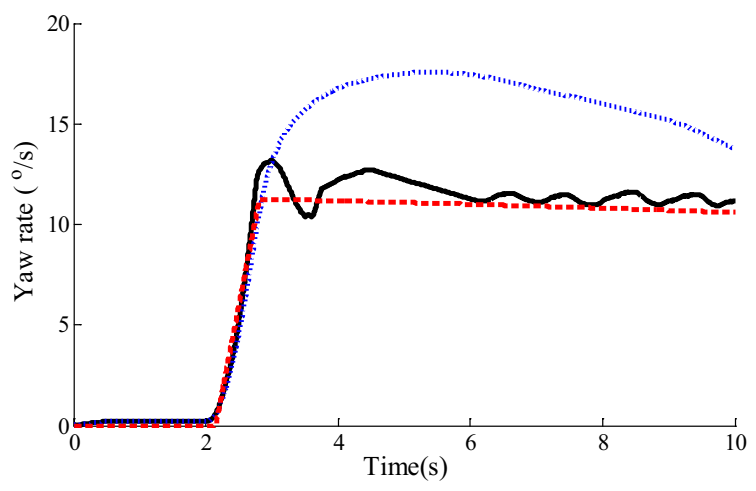

a Yaw rate on low friction road (friction coefficent $0.6,70 \mathrm{~km} / \mathrm{h}$ )

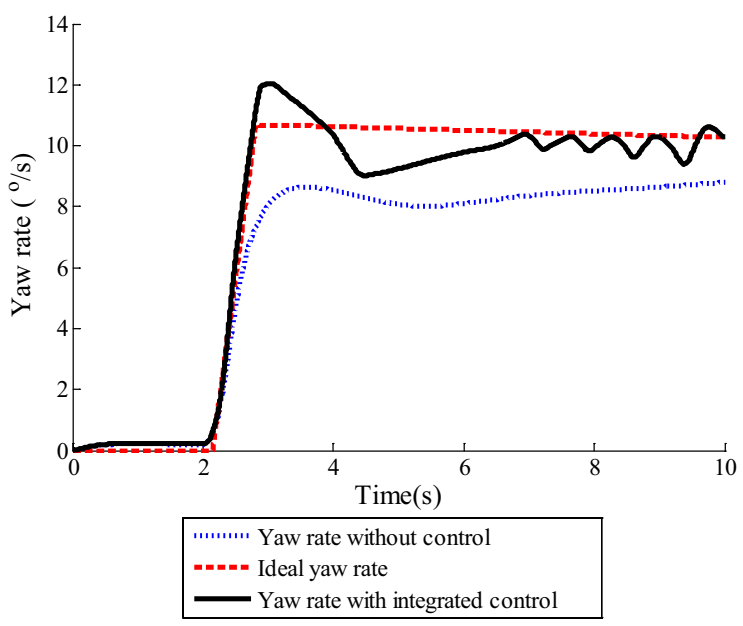

b Yaw rate on low friction road (friction coefficent $0.3,70 \mathrm{~km} / \mathrm{h}$ )

Figure 14 Yaw rate comparison on low friction roads

prevent understeering, braking on the inside wheels on axles after the CG point can generate better effects than braking on the front axles. (3) The largest yaw moment changes generated by braking on each wheel are limited not only by initial forces of the tires, ability of air braking system, and steering angle but also by distances between the axles and CG position. (4) In terms of braking wheel, when the root of the quadratic sum of braking force and lateral force is equal to the radius of Kamm's Circle, braking wheels on the rear axle need a complex control logic. When the truck is in the danger of drifting, braking on front axles is a better choice.

For active steering control: (1) To generate an extra outward yaw moment, if active steering acts on the axles before the CG point, the steering angle needs to be outward and vice versa. (2) The extra yaw moment depends on the vertical forces of tires and distance of the active steering axle to the CG. (3) During the steering period, an extra detrimental lateral acceleration is generated, affecting vehicle stability. (4) Regarding the truck in this paper, the best AS control speed is $20^{\circ}$ /s.

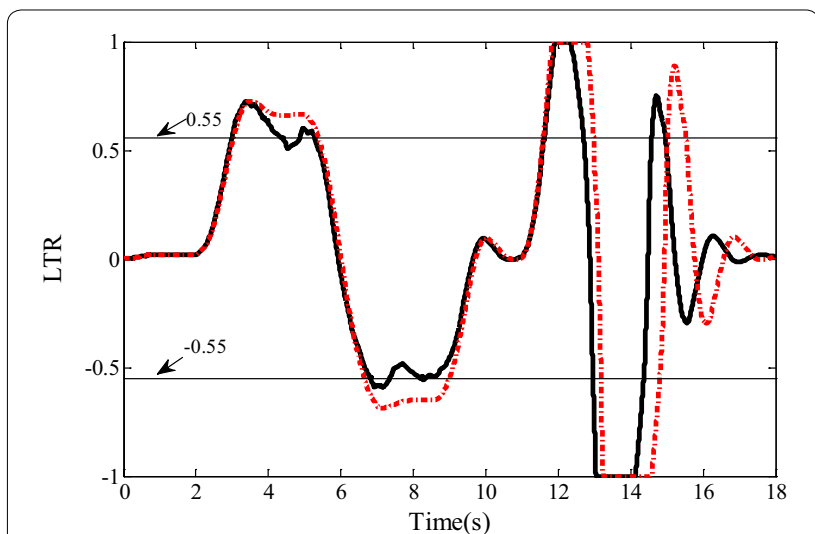

a LTR with $20000 \mathrm{~kg}$ cargo weight under $70 \mathrm{~km} / \mathrm{h}$

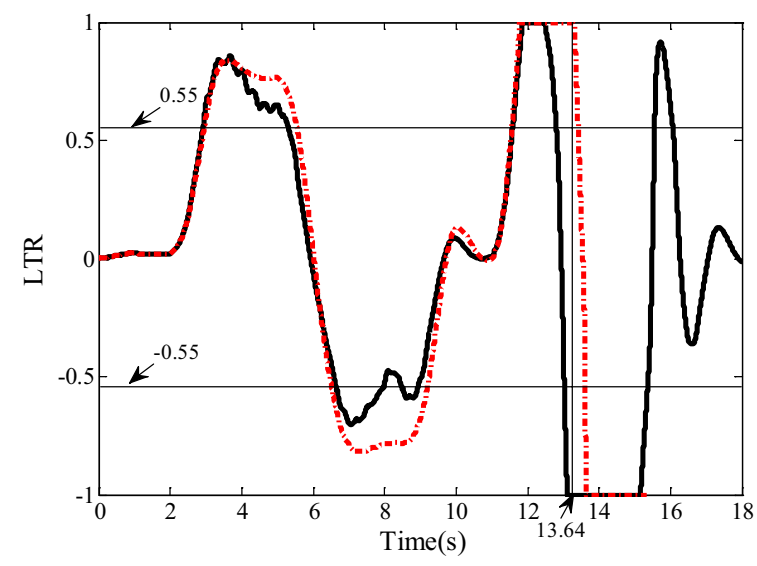

TR with integrated control =-1- LTR without control

b LTR with $20000 \mathrm{~kg}$ cargo weight under $80 \mathrm{~km} / \mathrm{h}$

Figure 15 LTR comparison with different cargo weights

In the future research, a multi-axle active steering will be studied. The trajectory tracking based on DB and AS will also be considered. Moreover, the states of the truck such as roll angle, roll angle rate, yaw rate, and accelerations are assumed partially known from sensors. Thus, the estimation method will be considered as well. The ultimate objective is to develop an integrated control system that is suitable for trucks with different numbers of axles and tractor semitrailers with a minimum number of sensors.

\section{Authors' Contributions}

BZ and CZ were in charge of the whole trial; BZ, GC wrote the manuscript; TX and $\mathrm{YH}$ assisted with sampling and laboratory analyses. All authors read and approved the final manuscript.

\section{Author Details}

${ }^{1}$ College of Automotive Engineering, Jilin University, Changchun 130022, China. ${ }^{2}$ State Key Laboratory of Automotive Simulation and Control, Jilin University, Changchun 130022, China. ${ }^{3}$ College of Mechanical and Mechatronics Engineering, University of Waterloo, Waterloo, ON N2L 3G1, Canada. 


\section{Authors' Information}

Buyang Zhang, born in 1989, is currently a PhD candidate at College of Automotive Engineering, Jilin University, China. His research interests include vehicle dynamic, vehicle stability control, intelligent tire, non-pneumatic tire.

Changfu Zong, born in 1962, is currently a professor at State Key Laboratory of Automotive Simulation and Control, Jilin University, China.

Guoying Chen, born in 1984, is currently a master candidate at State Key Laboratory of Automotive Simulation and Control, Jilin University, China.

Yanjun Huang, born in 1986, is currently a post doctor at University of Water100, Canada. His research interests include vehicle stability control, intelligent vehicle and new energy vehicle. E-mail: huangyanjun404@gmail.com.

Ting Xu, born in 1990, is currently a PhD candidate at College of Automotive Engineering, Jilin University, China. Her research interests include vehicle stability control, intelligent tire, non-pneumatic tire, tire modeling.

\section{Acknowledgements}

The authors sincerely thanks to Professor Haitao Ding of Jilin University for his critical discussion and reading during manuscript preparation.

\section{Competing interests}

The authors declare that they have no competing interests.

\section{Funding}

Supported by National Natural Science Foundation of China (Grant No. 51505178) and China Postdoctoral Science Foundation (Grant No. 2014M561289).

\section{Appendix}

\section{List of abbreviations}

\begin{tabular}{ll}
\hline Abbreviations & Details \\
\hline DB & Differential braking \\
AS & Active steering \\
ESC & Electronic stability control \\
DYC & Direct yaw moment control \\
AFS & Active front steering \\
ARS & Active rear steering \\
MPC & Model predictive control \\
LTR & Lateral load transfer ratio \\
\hline
\end{tabular}

\section{Nomenclature}

\begin{tabular}{lll}
\hline Symbols & Explanation & Details \\
\hline$\mu$ & Coefficient of friction & $0.85,0.6,0.3$ \\
$g$ & Acceleration of gravity & $9.8 \mathrm{~m} / \mathrm{s}^{2}$ \\
$m$ & Total vehicle mass & $m=m_{V}+\sum_{i=1}^{4} m_{a i}+m_{c} \quad i=1,2,3,4$ \\
& & \\
$m_{s}$ & Mass of sprung mass & $m_{s}=m_{v}+m_{c}$ \\
$m_{a i}$ & Axle mass & $m_{a 1}=570 \mathrm{~kg}$, \\
& & $m_{a 2}=m_{a 3}$ \\
& & $4457 \mathrm{~kg}$ \\
$m_{V}$ & Vehicle body mass & \\
$m_{c}$ & Cargo load mass & $5000 \mathrm{~kg}, 20000 \mathrm{~kg}$ \\
$m_{i}$ & Half of the cargo mass & $m_{c} / 2, i=2,3$ \\
& in Part 2 and Part 3 & \\
\hline
\end{tabular}

\begin{tabular}{|c|c|c|}
\hline Symbols & Explanation & Details \\
\hline$v_{x}$ & Vehicle velocity & \\
\hline$\delta_{i}$ & $\begin{array}{l}\text { Steering angle of the } \\
\text { ith axle }\end{array}$ & $i=1,2,3,4$ \\
\hline$\alpha_{l i, r i}$ & $\begin{array}{l}\text { Sideslip angle of the } \\
\text { tires }\end{array}$ & $i=1,2,3,4$ \\
\hline$\beta$ & Side slip angle & \\
\hline$\dot{\psi}$ & Yaw rate & \\
\hline$\dot{\psi}_{d}$ & Desired yaw rate & \\
\hline$\varphi$ & Roll angle & \\
\hline$a_{x}, a_{y}$ & $\begin{array}{l}\text { Longitudinal and } \\
\text { lateral acceleration }\end{array}$ & \\
\hline$a_{\text {yas }}$ & $\begin{array}{l}\text { Lateral acceleration } \\
\text { after active steering }\end{array}$ & \\
\hline$F_{y_{\text {sum }}}$ & Sum of lateral forces & \\
\hline$F_{y r i, y l i}$ & Lateral force of tire & $i=1,2,3,4$, tire coordinate system \\
\hline$F_{y r i_{0}, y i_{0}}$ & $\begin{array}{l}\text { Lateral forces of tires } \\
\text { without the effects } \\
\text { from longitudinal } \\
\text { forces }\end{array}$ & $i=1,2,3,4$, tire coordinate system \\
\hline$F_{z l i_{0}, z r_{0}}$ & $\begin{array}{l}\text { Initial left and right } \\
\text { side vertical tire } \\
\text { forces }\end{array}$ & $i=1,2,3,4$ \\
\hline$F_{z r i, z l i}$ & Vertical forces of tires & $i=1,2,3,4$ \\
\hline$F_{x r i, x l i}$ & $\begin{array}{l}\text { Longitudinal force of } \\
\text { wheel }\end{array}$ & $i=1,2,3,4$, tire coordinate system \\
\hline$F_{x r i_{\max }, l l_{\max }}$ & Best braking forces & $i=1,2,3,4$, tire coordinate system \\
\hline$K_{b i}$ & $\begin{array}{l}\text { Stiffness of anti-roll } \\
\text { bar }\end{array}$ & $K_{b i}=73020 \mathrm{Nm} / \mathrm{rad}, i=1,2,3,4$ \\
\hline$K_{i}$ & $\begin{array}{l}\text { Suspension stiffness } \\
\text { of parts }\end{array}$ & $K_{i}=250000 \mathrm{Nm} / \mathrm{rad}, i=1,2,3$ \\
\hline$C_{i}$ & $\begin{array}{l}\text { Suspension damp- } \\
\text { ness of parts } i\end{array}$ & $C_{i}=33000 \mathrm{Nms} / \mathrm{rad}, i=1,2,3,4$ \\
\hline K & $\begin{array}{l}\text { Suspension stiffness } \\
\text { of whole truck }\end{array}$ & $3700000 \mathrm{Nm} / \mathrm{rad}$ \\
\hline C & $\begin{array}{l}\text { Suspension damp- } \\
\text { ness of whole truck }\end{array}$ & $595000 \mathrm{Nms} / \mathrm{rad}$ \\
\hline H & Wheel track & $2.03 \mathrm{~m}$ \\
\hline Iv & $\begin{array}{l}\text { Distance between CG } \\
\text { point and front axle }\end{array}$ & $4.52 \mathrm{~m}, 5.02 \mathrm{~m}$ \\
\hline$I_{V 1}$ & $\begin{array}{l}\text { Distance between } \mathrm{cg}_{1} \\
\text { point and front axle }\end{array}$ & $1.113 \mathrm{~m}$ \\
\hline$l_{i}$ & $\begin{array}{l}\text { Distance between } \\
\text { first axle and ith axle }\end{array}$ & $\begin{array}{l}I_{1}=4.194 \mathrm{~m} \\
I_{2}=6 \mathrm{~m} \\
I_{3}=7.806 \mathrm{~m} \\
i=2,3,4\end{array}$ \\
\hline lri & $\begin{array}{r}\text { Distance between CG } \\
\text { point and rear axles }\end{array}$ & $I_{r i}=I_{i}-I_{v}, i=1,2,3$ \\
\hline$I_{r 1 i}$ & $\begin{array}{l}\text { Distance between } \\
\text { cgl point and }(i-1) \\
\text { th axle }\end{array}$ & $I_{r 1 i}=I_{i}-I_{v 1,} i=1,2,3$ \\
\hline$h$ & $\begin{array}{l}\text { Distance between CG } \\
\text { to roll axle }\end{array}$ & $1.25 \mathrm{~m}, 1.9 \mathrm{~m}$ \\
\hline$h_{r i}$ & $\begin{array}{l}\text { Distance between } \\
\text { cg;to roll axle of } \\
\text { different parts }\end{array}$ & $\begin{array}{l}h_{r 1}=0.5 \mathrm{~m}, h_{r 2}=h_{r 3}=-0.5 \mathrm{~m}, \\
\quad i=1,2,3\end{array}$ \\
\hline
\end{tabular}




\begin{tabular}{|c|c|c|}
\hline Symbols & Explanation & Details \\
\hline$h_{i}$ & $\begin{array}{l}c g_{i} \text { height of different } \\
\text { parts }\end{array}$ & $\begin{array}{l}h_{1}=1.173 \mathrm{~m}, h_{2}=h_{3}=1.475 \mathrm{~m} \\
h_{1}=1.173 \mathrm{~m}, h_{2}=h_{3}=2.15 \mathrm{~m}\end{array}$ \\
\hline$L_{k}$ & Length of the cargo & $L_{k}=7 \mathrm{~m}$ \\
\hline$s L_{c}$ & $\begin{array}{l}\text { Center of the cargo } \\
\text { mass to the first axle }\end{array}$ & $L_{c}=6 \mathrm{~m}$ \\
\hline$k_{t i}$ & $\begin{array}{l}\text { Correction factors for } \\
\text { wheels of rear axles } \\
\text { (double tires in each } \\
\text { side) }\end{array}$ & $k_{t i}=1.4, \quad i=2,3,4$ \\
\hline$P_{\text {hy2 }}$ & $\begin{array}{l}\text { 315/80 R22. } 5 \text { tires } \\
\text { parameters }\end{array}$ & -0.0020257 \\
\hline$P_{v y 1}$ & $\begin{array}{l}\text { 315/80 R22. } 5 \text { tires } \\
\text { parameters }\end{array}$ & 0.015216 \\
\hline$P_{v y 2}$ & $\begin{array}{l}\text { 315/80 R22. } 5 \text { tires } \\
\text { parameters }\end{array}$ & -0.010365 \\
\hline$F_{z O}$ & $\begin{array}{l}\text { 315/80 R22. } 5 \text { tires } \\
\text { parameters }\end{array}$ & 3500 \\
\hline$P_{c y 1}$ & $\begin{array}{l}\text { 315/80 R22. } 5 \text { tires } \\
\text { parameters }\end{array}$ & 1.5874 \\
\hline$P_{d y 2}$ & $\begin{array}{l}\text { 315/80 R22. } 5 \text { tires } \\
\text { parameters }\end{array}$ & -0.075004 \\
\hline$P_{d y 1}$ & $\begin{array}{l}\text { 315/80 R22. } 5 \text { tires } \\
\text { parameters }\end{array}$ & 0.73957 \\
\hline$J_{m a}$ & $\begin{array}{l}\text { Factor for transform- } \\
\text { ing the extra yaw } \\
\text { moment to the vari- } \\
\text { ation of yaw angle }\end{array}$ & $10000 \mathrm{kgm}^{2 \Delta} \dot{\psi}=\Delta M_{z} / J_{m a}$ \\
\hline$K_{\dot{\psi}}$ & Gain for ideal yaw rate & 0.0025 \\
\hline$J_{x}$ & $\begin{array}{l}\text { Rotational inertia of } \\
\text { truck to roll axle }\end{array}$ & $54286 \mathrm{kgm}^{2}, 84287 \mathrm{kgm}^{2}$ \\
\hline$F_{y s}$ & $\begin{array}{l}\text { Lateral force from slid- } \\
\text { ing mode control }\end{array}$ & \\
\hline$M_{z s}$ & $\begin{array}{l}\text { Yaw moment from } \\
\text { sliding mode } \\
\text { control }\end{array}$ & \\
\hline$J_{z}$ & $\begin{array}{l}\text { Rotational inertia of } \\
\text { truck to } Z \text { axle }\end{array}$ & $141694 \mathrm{kgm}^{2}, 228694 \mathrm{kgm}^{2}$ \\
\hline$r$ & Radius of tire & $0.538 \mathrm{~m}$ \\
\hline Jytire & $\begin{array}{l}\text { Rotational inertia of } \\
\text { tire to y axle }\end{array}$ & $5000 \mathrm{kgm}^{2}$ \\
\hline$\kappa_{r i, l i}$ & $\begin{array}{l}\text { Slip ratio of the } \\
\text { wheels }\end{array}$ & $i=1,2,3,4$ \\
\hline$\kappa_{d r i, d l i}$ & $\begin{array}{l}\text { Desired slip ratio of } \\
\text { the wheels }\end{array}$ & $i=1,2,3,4$ \\
\hline$I_{s 1}$ & $\begin{array}{l}\text { Distance between } \\
\text { the first separation } \\
\text { point and first axle }\end{array}$ & \\
\hline$I_{c i}$ & $\begin{array}{l}\text { Distances between } \\
\mathrm{Cg}_{2} \text { and second axle } \\
\text { and } c g_{3} \text { and the } \\
\text { third axle }\end{array}$ & $i=2,3$ \\
\hline
\end{tabular}

\section{Simplified Magic Formula}

Equation (50) is the simplified Magic formula of the tire model. The details are in the Nomenclature.

$$
F_{y}=k_{t}\left(D_{y}\left(C_{y}\left(B_{y} \alpha\right)\right)+S_{v y}\right) \text {, }
$$

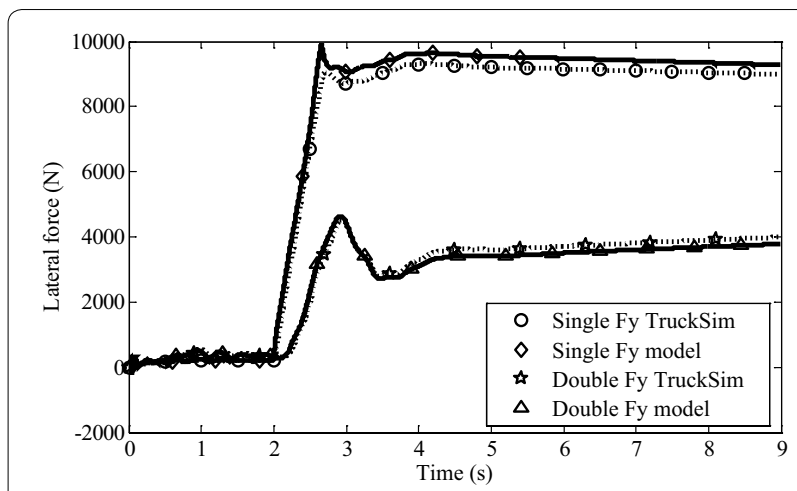

Figure 16 Comparison of simplified model and lateral forces from TruckSim

where

$$
\begin{aligned}
& S_{h y}=\left(P_{h y 1}+P_{h y 2} d f_{z}\right), \quad S_{v y}=F_{z}\left(P_{v y 1}+P_{v y 2} d f_{z}\right), \\
& C_{F y}=2 P_{k y 1} F_{z o} \arctan \left(\frac{F_{z}}{P_{k y 2} F_{z o}}\right), \quad d f_{z}=\frac{\left(F_{z}-F_{z o}\right)}{F_{z o}}, \\
& \alpha_{y}=\alpha+S_{h y}, \quad C_{y}=P_{c y 1} \mu_{y}=\left(P_{d y 1}+P_{d y 2} d f_{z}\right), \\
& D_{y}=\mu_{y} F_{z}, \quad B_{y}=\frac{C_{F y}}{C_{y} D_{y}} .
\end{aligned}
$$

Figure 16 shows the comparison of lateral forces between the simplified tire model and TruckSim. The biggest deviation in Figure 15 is under 10\%.

\section{Gains in Eq. (31)}

$$
\begin{aligned}
& K_{\varphi}=\frac{2 K_{1}+2 K_{2}+2 K_{3}+2 h_{r 2} m_{2} g+2 h_{r 3} m_{3} g+2 h_{r 1} m_{v} g}{H \sum_{i=1}^{4}\left(F_{z l i_{0}}+F_{z r i_{0}}\right)}+\cdots \\
& +\frac{2 K_{b 1}+2 K_{b 2}+2 K_{b 3}+2 K_{b 4}}{H \sum_{i=1}^{4}\left(F_{z l i_{0}}+F_{z r i_{0}}\right)}-\cdots \\
& -\frac{4 l_{v 1}\left(K_{1}+h_{r 1} m_{v} g\right)}{H\left(\frac{l_{r 11}}{2}+l_{v 1}\right) \sum_{i=1}^{4}\left(F_{z l i_{0}}+F_{z r i_{0}}\right)}-\cdots \\
& -\frac{4\left(\frac{l_{c 2}\left(K_{2}+h_{r 2} m_{2} g\right)}{H}-\frac{l_{r 11} l_{v 1}\left(K_{1}+h_{r 1} m_{v} g\right)}{H\left(l_{r 11}+2 l_{v 1}\right)}\right)}{\left(\frac{l_{r 12}}{2}-\frac{l_{r 11}}{2}+\frac{l_{c 2}}{2}\right)\left(l_{r 12}-l_{r 13}\right) \sum_{i=1}^{4}\left(F_{z l i_{0}}+F_{z r i_{0}}\right)} \times \cdots \\
& \times \frac{\left(\frac{l_{r 11}}{2}+\frac{l_{r 12}}{2}-l_{r 13}+\frac{l_{c 2}}{2}\right)}{\left(\frac{l_{r 12}}{2}-\frac{l_{r 11}}{2}+\frac{l_{c 2}}{2}\right)\left(l_{r 12}-l_{r 13}\right) \sum_{i=1}^{4}\left(F_{z l l_{0}}+F_{z r i_{0}}\right)}+\cdots \\
& \left.+\frac{\frac{4\left(K_{3}+h_{r 3} m_{3} g\right)\left(l_{r 12}-l_{r 13}+l_{c 3}\right)}{H}}{4}, l_{r 12}-l_{r 13}\right) \sum_{i=1}^{4}\left(F_{z l i_{0}}+F_{z r i_{0}}\right)
\end{aligned}
$$




$$
\begin{aligned}
& K_{\dot{\varphi}}=\frac{2 C_{1}+2 C_{2}+2 C_{3}}{H \sum_{i=1}^{4}\left(F_{z l i_{0}}+F_{z r i_{0}}\right)}-\frac{4 C_{1} l_{v 1}}{H\left(\frac{l_{r 11}}{2}+l_{v 1}\right) \sum_{i=1}^{4}\left(F_{z l i_{0}}+F_{z r i_{0}}\right)}-\cdots \\
& -4 \frac{\left(\frac{C_{2} l_{c 2}}{H}-\frac{C_{1} l_{r 11} l_{v 1}}{H\left(l_{r 11}+2 l_{v 1}\right)}\right)\left(\frac{l_{r 11}}{2}+\frac{l_{r 12}}{2}-l_{r 13}+\frac{l_{c 2}}{2}\right)}{\left(\frac{l_{r 12}}{2}-\frac{l_{r 11}}{2}+\frac{l_{c 2}}{2}\right)\left(l_{r 12}-l_{r 13}\right) \sum_{i=1}^{4}\left(F_{z i_{0}}+F_{z r i_{0}}\right)}+\cdots \\
& +\frac{4 C_{3}\left(l_{r 12}-l_{r 13}+l_{c 3}\right)}{H\left(l_{r 12}-l_{r 13}\right) \sum_{i=1}^{4}\left(F_{z l i_{0}}+F_{z r i_{0}}\right)},
\end{aligned}
$$

$$
\begin{aligned}
K_{a y} & =\frac{2 h_{2} m_{2}+2 h_{3} m_{3}+2 h_{1} m_{v}}{H \sum_{i=1}^{4}\left(F_{z l i_{0}}+F_{z r i_{0}}\right)}-\cdots \\
& -\frac{4 h_{1} l_{v 1} m_{v}}{H\left(\frac{l_{r 11}}{2}+l_{v 1}\right) \sum_{i=1}^{4}\left(F_{z l i_{0}}+F_{z r i_{0}}\right)}-\cdots \\
-4 & \frac{\left(\frac{h_{2} l_{c 2} m_{2}}{H}-\frac{h_{1} l_{r 11} l_{v 1} m_{v}}{H\left(l_{r 11}+2 l_{v 1}\right)}\right)\left(\frac{l_{r 11}}{2}+\frac{l_{r 12}}{2}-l_{r 13}+\frac{l_{c 2}}{2}\right)}{\left(\frac{l_{r 12}}{2}-\frac{l_{r 11}}{2}+\frac{l_{c 2}}{2}\right)\left(l_{r 12}-l_{r 13}\right) \sum_{i=1}^{4}\left(F_{z l i_{0}}+F_{z r i_{0}}\right)}+\cdots \\
+ & \frac{4 h_{3} m_{3}\left(l_{r 12}-l_{r 13}+l_{c 3}\right)}{H\left(l_{r 12}-l_{r 13}\right) \sum_{i=1}^{4}\left(F_{z l i_{0}}+F_{z r i_{0}}\right)} .
\end{aligned}
$$

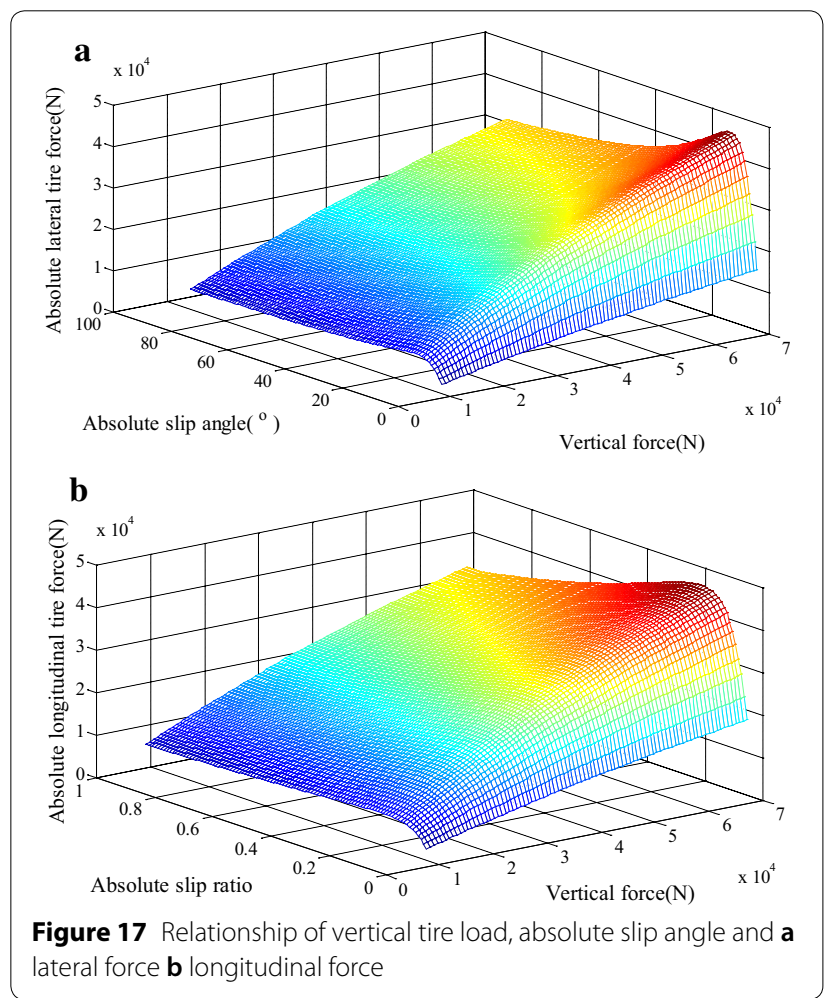

\section{Maps for Searching}

The longitudinal slip ratio of each wheel is searched in a map based on vertical forces of tires and braking forces from optimization. The map in Figure 17 is obtained from TruckSim.

\section{Existence of the Sliding Mode Controls}

1) Reaching law Eq. (36)

The Lyapunov candidate function is selected as $V$, and the existence of the discrete sliding mode control law should satisfy Eq. (54), which is equal to the arrival condition in Eq. (55) and is transferred to Eq. (56) [34]. For simplicity, Eq. (56) can be represented by Eq. (57). If $0<q<1 / T$ and $\varepsilon>0$, Eq. (54) is satisfied. Regarding the sliding mode control system, Eq. (56) can be transferred into Eq. (58), where $I$ is a $2 \times 2$ unit matrix. Inserting the parameters from Eqs. (36) into (58), it is clear that Eq. (54) can be satisfied, and the sliding mode control system exists.

$$
\begin{aligned}
& V(k+1)-V(k)=\frac{1}{2}\left(S(k+1)^{2}-S(k)^{2}\right)<0 \\
& V(k)=\frac{1}{2} S(k)^{2}, \\
& |S(k+1)|<|S(k)|, \\
& \left\{\begin{array}{l}
{[S(k+1)-S(k)] \operatorname{sat}(S(k))<0,} \\
{[S(k+1)+S(k)] \operatorname{sat}(S(k))>0,}
\end{array}\right. \\
& \quad s(k+1)-s(k)=-q T s(k)-\varepsilon T \operatorname{sat}(s(k)), \\
& \quad S(k+1)-S(k)=\left(k_{s}-I\right) S(k)-\left[\begin{array}{l}
k_{s m 1} \operatorname{sat}\left(S_{1}(k)\right) \\
k_{s m 2} \operatorname{sat}\left(S_{2}(k)\right)
\end{array}\right],
\end{aligned}
$$




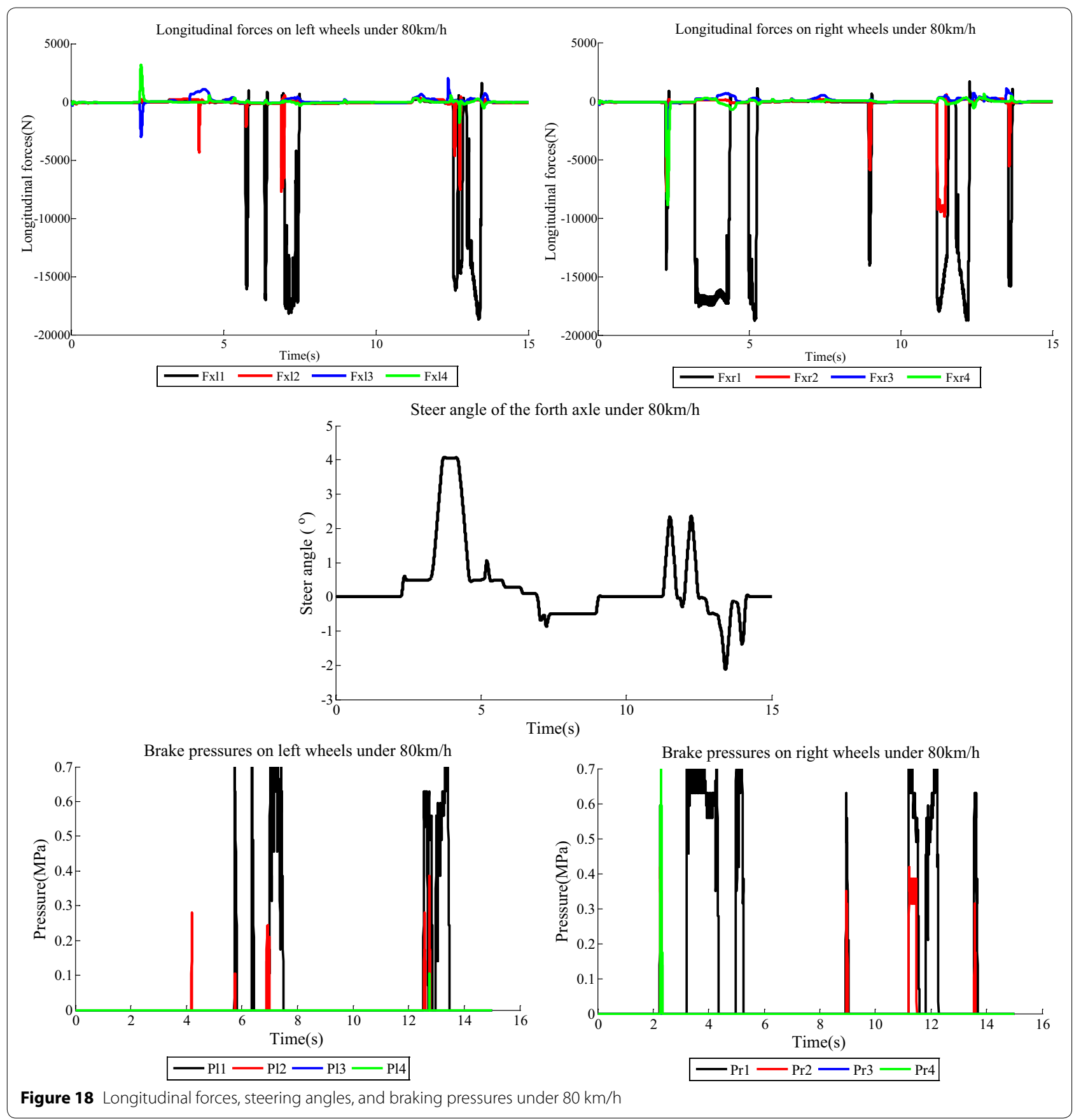

2) Eq. (48)

The same with Eqs. (54)-(58). The Lyapunov candidate function is as Eq. (54). Based on Eq. (57), Eq. (54) is satisfied when $0<q<1 / T, \varepsilon>0$. Equation (56) can be transferred to Eq. (59). The parameters of Eq. (48) are transferred into Eq. (59). Eq. (60) can be satisfied, and the sliding mode control system exists.

$$
\begin{aligned}
& S_{\text {brasri,brasli }}(k+1)-S_{b s r i, b s l i}(k)=\cdots \\
& \left(k_{b s}-1\right) S_{b s r i, b s l i}(k)-k_{b s m} \operatorname{sgn}\left(S_{b s r i, b s l i}(k)\right), \\
& 0<q T=-\left(1-k_{b s}\right)<1, \quad \varepsilon=k_{b s m} / T>0 .
\end{aligned}
$$

\section{Additional Figures of Control Results}

The longitudinal forces on each wheel and steering angle of the fourth axle under $80 \mathrm{~km} / \mathrm{h}$ are shown in Figure 18. 


\section{Publisher's Note}

Springer Nature remains neutral with regard to jurisdictional claims in published maps and institutional affiliations.

Received: 10 April 2018 Accepted: 23 January 2019

Published online: 21 February 2019

\section{References}

[[1] Haitao Ding, Amir Khajepour, Yanjun Huang. A novel tripped rollover prevention system for commercial trucks with air suspensions at low speeds. Proceedings of the Institution of Mechanical Engineers, Part D: Journal of Automobile Engineering, 2018, 232(11): 1516-1527.

[2] Yubiao Zhang, Yanjun Huang, Yanjun Hong, et al. A comparative study of equivalent modelling for multi-axle vehicle. Vehicle System Dynamics, 2018, 56(3): 443-460.

[3] Yu-biao Zhang, A Khajepour, Y J Huang. Multi-axle/articulated bus dynamics modeling: a reconfigurable approach. Vehicle System Dynamics, 2018, 56(9): 1315-1343.

[4] Anton T van Zanten. Evolution of electronic control systems for improving the vehicle dynamic behavior. International Symposium on Advanced Vehicle Control, 2002: 1-9.

[5] A Goodarzi, B Naderkhani, E Esmailzadeh. Direct yaw moment controller design for vehicle dynamic control systems. Proceedings of the IASTED International Conference on Modelling, Simulation and Optimization, July 2-4, 2003: 120-124.

[6] Zhuoping Yu, Renxie Zhang, Xiong Lu, et al. Robust adaptive anti-slip regulation controller for a distributed-drive electric vehicle considering the driver's intended driving torque. Proceedings of the Institution of Mechanical Engineers, Part D: Journal of Automobile Engineering, 2018, 232(4): 562-576

[7] J Ackermann, T Bünte, D Odenthal. Advantages of active steering for vehicle dynamics control. Mocm, 1999. https://www.researchgate.net/profi le/Dirk_Odenthal/publication/243424257_Advantages_Of_Active_Steer ing_For_Vehicle_Dynamics_Control/links/540f0bed0cf2d8daaad089e1. pdf.

[8] J Yoon, W Cho, J Kang, et al. Design and evaluation of a united chassis control system for rollover prevention and vehicle stability improvement on a virtual test track. Control Engineering Practice, 2010, 18(6): 585-597.

[9] Xiaojian Wu, Bing Zhou, Guilin Wen, et al. Intervention criterion and control research for active front steering with consideration of road adhesion. Vehicle System Dynamics, 2018, 56(4): 553-578.

[10] M Doumiati, O Sename, L Dugard, et al. Integrated vehicle dynamics control via coordination of active front steering and rear braking. European Journal of Control, 2013, 19(2): 144-145.

[11] A Tavasoli, M Naraghi, H Shakeri. Optimized coordination of brakes and active steering for a 4WS passenger car. Isa Transactions, 2012, 51(5): 573-583.

[12] Y Shibahata, K Shimada, T Tomari. Improvement of vehicle maneuverability by direct yaw moment control. Vehicle System Dynamics, 1993, 22(6): 465-481.

[13] K Koibuchi, M Yamamoto, Y Fukada, et al. Vehicle stability control in limit cornering by active brake. SAE Technical Paper, 1995, 16(3): 323.

[14] M Yang, X H Gao, H Wang, et al. Simulation analysis of multi-axle vehicle braking stability based on all-wheel active steering technology. ICIMA 2010-2010 2nd International Conference on Industrial Mechatronics and Automation, Wuhan, China, 2010, 1: 366-369.

[15] Balázs Varga, Balázs Kulcsár, LeoLaine, et al. Robust tracking controller design for active dolly steering. Proceedings of the Institution of Mechanical Engineers, Part D: Journal of Automobile Engineering, 2018, 232(5): 695-706.

[16] B Li, Rakheja S, Y Feng. Enhancement of vehicle stability through integration of direct yaw moment and active rear steering. Proceedings of the Institution of Mechanical Engineers, Part D: Journal of Automobile Engineering, 2016, 230(6): 830-840.

[17] C Bardawil, R Talj, C Francis, et al. Integrated vehicle lateral stability control with different coordination strategies between active steering and differential braking. 17th International IEEE Conference on Intelligent Transportation Systems \& The Asia-Pacific Council on Systems Engineering Conference, 2014: 314-319.

[18] H Mirzaeinejad, M Mirzaei, R Kazemi. Enhancement of vehicle braking performance on split- $\mu$ roads using optimal integrated control of steering and braking systems. Proceedings of the Institution of Mechanical Engineers Part K: Journal of Multi-body Dynamics, 2015, 230(4): 401-415.

[19] Anne Von Vietinghoff, HY Lu, U Kiencke. Detection of critical driving situations using phase plane method for vehicle lateral dynamics control by rear wheel steering. IFAC Proceedings Volumes, 2008, 41 (2): 5694-5699.

[20] Jun-jie He, D A Crolla, M C Levesley, et al. Coordination of active steering, driveline, and braking for integrated vehicle dynamics control. Proceedings of the Institution of Mechanical Engineers, Part D: Journal of Automobile Engineering, 2006, 220(10): 1401-1420.

[21] Hao Zhang, Xiansheng Li, Shuming Shi, et al. Phase plane analysis for vehicle handling and stability. International Journal of Computational Intelligence Systems, 2011, 4(6): 1179-1186.

[22] S Çăglar Bașlamișli, I Emre Köse, Günay Anlaç. Handling stability improvement through robust active front steering and active differential control. Vehicle System Dynamics, 2011, 49(5): 657-683.

[23] S Ç Baslamisli, I Emre Köse, G Anlaş. Gain-scheduled integrated active steering and differential control for vehicle handling improvement. Vehicle System Dynamics, 2009, 47(1): 99-119.

[24] Y Zeyada, D Karnopp, M El-Arabi, et al. A combined active-steering differential-braking yaw rate control strategy for emergency maneuvers. SAE Technical Papers, 1998.

[25] S Di Cairano, H E Tseng, D Bernardini, et al. Vehicle yaw stability control by coordinated active front steering and differential braking in the tire sideslip angles domain. IEEE Transactions on Control Systems Technology, 2013, 21(4): 1236-1248.

[26] Bing Zhu, Qi Piao, Jian Zhao, et al. Integrated chassis control for vehicle rollover prevention with neural network time-to-rollover warning metrics. Advances in Mechanical Engineering, 2016, 8(2):1-13.

[27] M Choi, S B Choi, MPC for vehicle lateral stability via differential braking and active front steering considering practical aspects. Proceedings of the Institution of Mechanical Engineers Part D: Journal of Automobile Engineering, 2016, 230(4): 459-469.

[28] H Her, Y Koh, E Joa, et al. An integrated control of differential braking, front/rear traction, and active roll moment for limit handling performance. IEEE Transactions on Vehicular Technology, 2016, 65(6): 4288-4300.

[29] C Poussot-Vassal, O Sename, L Dugard. A LPV/H $\infty$, Global Chassis Controller for handling improvements involving braking and steering systems. 47th IEEE Conference on Decision and Control, Cancun, Mexico, 2008: 5366-5371.

[30] G Burgio, P Zegelaar. Integrated vehicle control using steering and brakes. International Journal of Control, 2006, 79(5): 534-541.

[31] S B Lu, Y N Li, S B Choi, et al. Integrated control on MR vehicle suspension system associated with braking and steering control. Vehicle System Dynamics, 2011, 49(1-2): 361-380.

[32] Jing Zhao, P K Wong, X B Ma, et al. Chassis integrated control for active suspension, active front steering and direct yaw moment systems using hierarchical strategy. Vehicle System Dynamics, 2017, 55(1): 72-103.

[33] Jian Wu, Shuo Cheng, Binhao Liu, et al. A human-machine-cooperativedriving controller based on AFS and DYC for vehicle dynamic stability. Energies, 2017, 10(11): 1-18.

[34] Shuo Cheng, L Li, J Chen. Fusion algorithm design based on adaptive SCKF and integral correction for side-slip angle observation. IEEE Transactions on Industrial Electronics, 2018, 65(7): 5754-5763.

[35] Armin Norouzi, Reza Kazemi, Shahram Azadi. Vehicle lateral control in the presence of uncertainty for lane change maneuver using adaptive sliding mode control with fuzzy boundary layer. Proceedings of the Institution of Mechanical Engineers Part I: Journal of Systems and Control Engineering 2018, 232(1): 12-28.

[36] Y J Huang, A Khajepour, M Khazraee, et al. A comparative study of the energy-saving controllers for automotive air-conditioning/refrigeration systems. Journal of Dynamic Systems, Measurement, and Control, 2017 139(1): 1-9. 